Supporting Information for

\title{
Synthesis of the C22-C40 Domain of the Azaspiracids
}

Zhigao Zhang, Yong Chen, Daniel Adu-Ampratwum, Antony A. Okumu, Nathaniel T. Kenton, Craig J. Forsyth ${ }^{*}$

Department of Chemistry \& Biochemistry, The Ohio State University, Columbus, Ohio 43210

forsyth@chemistry.ohio-state.edu

\section{Contents}

\section{General Methods}

Experimental Procedures and Characterization Data

\section{Literature References}

${ }^{1} \mathrm{H}$ NMR and ${ }^{13} \mathrm{C}$ NMR Spectra for all New Compounds 


\section{General Methods:}

Unless otherwise noted, all reactions were carried out under an argon atmosphere in over-dried glassware using standard syringe, cannula, and septa techniques. Dichloromethane, tetrahydrofuran, diethyl ether, toluene, and dimethylformamide were purified with a Pure Solv. MD-6 solvent purification system. Triethylamine, diisopropylethylamine, acetonitrile, and methanol were distilled from calcium hydride under nitrogen. All other solvents were used as received.

Analytical thin layer chromatography (TLC) was performed using $0.25 \mathrm{~mm}$ Silicycle silica gel $60 \mathrm{~F}_{254}$ plates. Solvents for chromatography are listed as volume: volume ratios. Optical rotations were measured on a Perkin-Elmer polarimeter. Nuclear magnetic resonance (NMR) spectra were recorded on a Bruker DPX 400 spectrometer, operating at $400 \mathrm{MHz}$ for ${ }^{1} \mathrm{H}$ NMR and $100 \mathrm{MHz}$ for ${ }^{13} \mathrm{C}$ NMR. Chemical shifts were reported in ppm on the $\delta$ scale relative to residual $\mathrm{CHCl}_{3}\left(\delta=7.28\right.$ for ${ }^{1} \mathrm{H} \mathrm{NMR}$ and $\delta=77.2$ for ${ }^{13} \mathrm{C}$ NMR) as an internal reference. The coupling constant values $(J)$ are in Hertz $(\mathrm{Hz})$. The following abbreviations have been used for signal multiplicities: s, singlet; $d$, doublet; $t$, triplet; q, quartet; m, multiplet; and br, broad. ESI mass spectra were measured on a Bruker MicroOTOF instrument. 


\section{(2S,4R,5S)-5-hydroxy-6-((4-methoxybenzyl)oxy)-4-methyl-3-oxohexan-2-yl benzoate (13)}<smiles>[R6]OC(C)C(=O)[C@@H](C)C(O)COC(C)C</smiles>

13

To a cooled $\left(-78{ }^{\circ} \mathrm{C}\right)$ solution of $c-\mathrm{Hex}_{2} \mathrm{BCl}(0.32 \mathrm{~g}, 1.5 \mathrm{mmol})$ in $\mathrm{Et}_{2} \mathrm{O}(4 \mathrm{ml})$ was added $\mathrm{Me}_{2} \mathrm{NEt}(0.2 \mathrm{~g}, 1.8 \mathrm{mmol})$, followed by ketone $\mathbf{1 2}^{1}(0.2 \mathrm{~g}, 1.0 \mathrm{mmol})$ in $\mathrm{Et}_{2} \mathrm{O}(4 \mathrm{~mL})$. The reaction mixture was warmed to $0{ }^{\circ} \mathrm{C}$ and stirred for $2 \mathrm{~h}$ before cooling to $-78{ }^{\circ} \mathrm{C}$.

The aldehyde $\mathbf{1 1}^{2}(0.7 \mathrm{~g}, 4.0 \mathrm{mmol})$ in $\mathrm{Et}_{2} \mathrm{O}(2 \mathrm{~mL})$ was added and the stirring continued for another $2 \mathrm{~h}$, before being transferred to a freezer $\left(-20^{\circ} \mathrm{C}\right)$ for $14 \mathrm{~h}$. the reaction was quenched at 0 ${ }^{\circ} \mathrm{C}$ by addition of $\mathrm{MeOH}(4 \mathrm{~mL})$, and $\mathrm{pH}=7$ aqueous buffer $(4 \mathrm{~mL}) . \mathrm{H}_{2} \mathrm{O}_{2}(4 \mathrm{~mL}, 30 \%)$ was then added and the stirring continued for $1 \mathrm{~h}$ before the addition of $\mathrm{H}_{2} \mathrm{O}(30 \mathrm{~mL})$ and $\mathrm{CH}_{2} \mathrm{Cl}_{2}(30 \mathrm{~mL})$. The aqueous phase was then extracted with $\mathrm{CH}_{2} \mathrm{Cl}_{2}(3 \times 30 \mathrm{~mL})$. The organic phases were dried over anhydrous $\mathrm{MgSO}_{4}$, filtered, and concentrated. The residue was purified by flash chromatography (hexanes-ethyl acetate, 5:1, v/v) to provide alcohol $13(0.38 \mathrm{~g}, 0.98 \mathrm{mmol}, 98 \%)$ as a colorless oil.

$\mathrm{R}_{\mathrm{f}}=0.2$ (Hexanes-Ethyl acetate, 3:1, v/v); ${ }^{1} \mathrm{H} \mathrm{NMR}\left(\mathrm{CDCl}_{3}, 400 \mathrm{MHz}\right): \delta 8.07(\mathrm{~m}, 2 \mathrm{H}), 7.54(\mathrm{t}, J$ $=7.4 \mathrm{~Hz}, 1 \mathrm{H}), 7.42(\mathrm{t}, J=7.8 \mathrm{~Hz}, 2 \mathrm{H}), 7.21(\mathrm{~d}, J=8.5 \mathrm{~Hz}, 2 \mathrm{H}), 6.86(\mathrm{~d}, J=8.5 \mathrm{~Hz}, 2 \mathrm{H}), 5.43(\mathrm{q}$, $J=7.0 \mathrm{~Hz}, 1 \mathrm{H}), 4.46\left(\mathrm{q}_{\mathrm{AB}}, \Delta v=24 \mathrm{~Hz}, J=11.5 \mathrm{~Hz}, 2 \mathrm{H}\right), 3.95(\mathrm{~m}, 1 \mathrm{H}), 3.75(\mathrm{~s}, 3 \mathrm{H}), 3.50(\mathrm{~m}$, 2H), $3.32(\mathrm{br}, 1 \mathrm{H}), 3.09(\mathrm{~m}, 1 \mathrm{H}), 1.54(\mathrm{~d}, J=7.0 \mathrm{~Hz}, 3 \mathrm{H}), 1.17(\mathrm{~d}, J=7.1 \mathrm{~Hz}, 3 \mathrm{H}) ;{ }^{13} \mathrm{C}$ NMR $\left(\mathrm{CDCl}_{3}, 100 \mathrm{MHz}\right): \delta 210.3,165.4,159.0,132.9,129.6,129.4,129.2,129.1,128.1,113.5,74.5$, 72.7, 72.0, 71.3, 54.9, 44.4, 15.1, 13.5; IR (neat): 3527, 2935, 1717, 1514, 1250, 1114, 1002, 819, 714; $[\alpha]_{\mathrm{D}}{ }^{25}+12.1\left(\mathrm{c} 2.1, \mathrm{CHCl}_{3}\right)$; HRMS-ESI $(\mathrm{m} / z)$ calculated for $\left[\mathrm{M}+\mathrm{Na}^{+}\right]: 409.1622$, found: 409.1621.

(2S,4R,5S)-5-((tert-butyldimethylsilyl)oxy)-6-((4-methoxybenzyl)oxy)-4-methyl-3-oxohexan2-yl benzoate (13a)

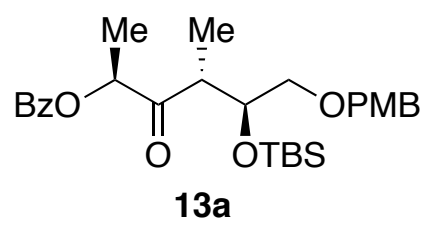

To a cooled $\left(-78{ }^{\circ} \mathrm{C}\right)$ solution of $\beta$-hydroxy ketone 13 (0.38 g, 0.98 $\mathrm{mmol})$ in $\mathrm{CH}_{2} \mathrm{Cl}_{2}(10 \mathrm{~mL})$ was added 2,6-lutidine $(0.46 \mathrm{ml}, 3.92$ mmol) and TBSOTf $(0.68 \mathrm{~mL}, 2.94 \mathrm{mmol})$ sequentially. The mixture was allowed to stir $1 \mathrm{~h}$ before saturated aqueous $\mathrm{NaHCO}_{3}$

$(10 \mathrm{~mL})$ was added. The aqueous phase was then extracted by diethyl ether $(3 \mathrm{x} 10 \mathrm{~mL})$. The combined organic phases were washed with brine. The organic phases were dried over anhydrous $\mathrm{Na}_{2} \mathrm{SO}_{4}$, filtered, and concentrated. The residue was purified by flash chromatography (hexanesethyl acetate, $30: 1, \mathrm{v} / \mathrm{v})$ to provide $13 \mathrm{a}(0.43 \mathrm{~g}, 0.86 \mathrm{mmol}, 89 \%)$ as a colorless oil.

$\mathrm{R}_{\mathrm{f}}=0.68$ (Hexanes-Ethyl acetate, 3:1, v/v); ${ }^{1} \mathrm{H}$ NMR $\left(\mathrm{CDCl}_{3}, 400 \mathrm{MHz}\right): \delta 8.09$ (m, 2H), 7.59 (m, 1H), $7.46(\mathrm{~m}, 2 \mathrm{H}), 7.24(\mathrm{~d}, J=8.7 \mathrm{~Hz}, 2 \mathrm{H}), 6.89(\mathrm{~d}, J=8.7 \mathrm{~Hz}, 2 \mathrm{H}), 5.48(\mathrm{q}, J=7.0 \mathrm{~Hz}, 1 \mathrm{H})$, 
$4.47\left(\mathrm{q}_{\mathrm{AB}}, \Delta v=31 \mathrm{~Hz}, J=11.6 \mathrm{~Hz}, 2 \mathrm{H}\right), 4.14(\mathrm{~m}, 1 \mathrm{H}), 3.82(\mathrm{~s}, 1 \mathrm{H}), 3.48(\mathrm{~m}, 2 \mathrm{H}), 3.24(\mathrm{~m}, 1 \mathrm{H})$, $1.52(\mathrm{~d}, J=7.0 \mathrm{~Hz}, 3 \mathrm{H}), 1.13(\mathrm{~d}, J=7.0 \mathrm{~Hz}, 3 \mathrm{H}), 0.86(\mathrm{~s}, 9 \mathrm{H}), 0.05(\mathrm{~s}, 3 \mathrm{H}),-0.01(\mathrm{~s}, 3 \mathrm{H}) ;{ }^{13} \mathrm{C}$ NMR ( $\left.\mathrm{CDCl}_{3}, 100 \mathrm{MHz}\right): \delta 208.4,165.7,159.2,133.1,130.2,129.8,129.7,129.3,128.3,113.7$, 74.7, 73.0, 72.8, 71.7, 55.2, 46.2, 25.8, 18.0, 15.3, 12.9, - 4.7, - 4.9; IR (neat): 2930, 1720, 1612, $1513,1452,1249,1114,835,712 ;[\alpha]_{\mathrm{D}}^{25}-4.24\left(\mathrm{c} 2.2, \mathrm{CHCl}_{3}\right)$; HRMS-ESI $(\mathrm{m} / z)$ calculated for $\left[\mathrm{M}+\mathrm{Na}^{+}\right]: 523.2486$, found: 523.2489 .

(2S,4S,5S)-5-((tert-butyldimethylsilyl)oxy)-6-((4-methoxybenzyl)oxy)-4-methylhexane-2,3diol (14)<smiles></smiles>

14
To a cooled $\left(-78{ }^{\circ} \mathrm{C}\right)$ solution of ketone 13a $(0.2 \mathrm{~g}, 0.4 \mathrm{mmol})$ in THF $(5 \mathrm{~mL})$ was added $\mathrm{LiBH}_{4}(176 \mathrm{mg}, 8 \mathrm{mmol})$. The mixture was allowed to warm up to ambient temperature slowly and stirred for 24 $\mathrm{h}$ before slow addition of $\mathrm{H}_{2} \mathrm{O}(5 \mathrm{~mL})$ and diethyl ether $(5 \mathrm{~mL})$. The aqueous phase was extracted with diethyl ether $(3 \times 10 \mathrm{~mL})$. The organic phases were dried over anhydrous $\mathrm{MgSO}_{4}$, filtered, and concentrated. The residue was purified by flash chromatography (hexanes-ethyl acetate, 4:1, v/v) to provide alcohol $14(153 \mathrm{~g}, 0.38 \mathrm{mmol}, 96 \%)$ as a colorless oil.

\section{(2R,3S)-3-((tert-butyldimethylsilyl)oxy)-4-((4-methoxybenzyl)oxy)-2-methylbutanal (15)}

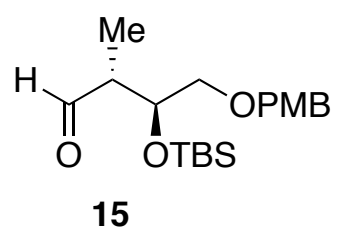

15

To a solution of $14(110 \mathrm{mg}, 0.28 \mathrm{mmol})$ in $\mathrm{MeOH}(1.5 \mathrm{~mL})$ and $\mathrm{H}_{2} \mathrm{O}$ $(0.7 \mathrm{~mL})$ was added $\mathrm{NaIO}_{4}(354 \mathrm{mg}, 1.68 \mathrm{mmol})$. The reaction mixture was stirred at ambient temperature for 30 min before the addition of $\mathrm{H}_{2} \mathrm{O}$ $(5 \mathrm{~mL})$ and diethyl ether $(5 \mathrm{~mL})$. The aqueous phase was extracted with diethyl ether $(3 \times 5 \mathrm{~mL})$. The organic phases were dried over anhydrous $\mathrm{MgSO}_{4}$, filtered, and concentrated. The residue was purified by flash chromatography (hexanes-ethyl acetate, 12:1, $\mathrm{v} / \mathrm{v})$ to provide aldehyde $15(95 \mathrm{mg}, 0.27 \mathrm{mmol}, 96 \%)$ as a colorless oil.

$\mathrm{R}_{\mathrm{f}}=0.61$ (Hexanes-Ethyl acetate, 3:1, v/v); ${ }^{1} \mathrm{H} \mathrm{NMR}\left(\mathrm{CDCl}_{3}, 400 \mathrm{MHz}\right): \delta 9.75(\mathrm{~d}, J=1.9 \mathrm{~Hz}$, 1H), $7.23(\mathrm{~d}, J=8.7 \mathrm{~Hz}, 2 \mathrm{H}), 6.88(\mathrm{~d}, J=8.7 \mathrm{~Hz}, 2 \mathrm{H}), 4.44(\mathrm{~s}, 2 \mathrm{H}), 4.14(\mathrm{~m}, 1 \mathrm{H}), 3.81(\mathrm{~s}, 3 \mathrm{H})$, $3.48(\mathrm{dd}, J=6.2 \mathrm{~Hz}, 1.4 \mathrm{~Hz}, 1 \mathrm{H}), 2.61(\mathrm{~m}, 1 \mathrm{H}), 1.11$ (d, $J=7.0 \mathrm{~Hz}, 3 \mathrm{H}), 0.89$ (s, 9H), 0.09 (s, $3 \mathrm{H}), 0.08(\mathrm{~s}, 3 \mathrm{H}) ;{ }^{13} \mathrm{C} \mathrm{NMR}\left(\mathrm{CDCl}_{3}, 100 \mathrm{MHz}\right): \delta 203.7,159.2,129.9,129.3,113.7,73.0,72.6$, 71.6, 55.2, 49.9, 25.7, 18.0, 9.9, - 4.5, - 5.1; IR (neat): 2953, 1724, 1612, 1513, 1463, 1249, 1102 , 836, 777; $[\alpha]_{\mathrm{D}}{ }^{25}-43.7\left(\mathrm{c} 1.9, \mathrm{CHCl}_{3}\right)$; HRMS-ESI $(\mathrm{m} / \mathrm{z})$ calculated for $\left[\mathrm{M}+\mathrm{Na}^{+}\right]: 375.1962$, found: 375.1962 . 
tert-butyl(((2S,3S)-5,5-dibromo-1-((4-methoxybenzyl)oxy)-3-methylpent-4-en-2-

yl)oxy)dimethylsilane (15a)<smiles>CCO[C@H](C=C(Br)Br)C(C)CO[Sb]</smiles>

$15 a$

To a cooled $\left(0{ }^{\circ} \mathrm{C}\right)$ solution of $\mathrm{CBr}_{4}(2.51 \mathrm{~g}, 7.56 \mathrm{mmol})$ in $\mathrm{CH}_{2} \mathrm{Cl}_{2}$ (25 mL) was added $\mathrm{Ph}_{3} \mathrm{P}$ (3.96 g, $\left.15.1 \mathrm{mmol}\right)$. The mixture was allowed to stir $30 \mathrm{~min}$ before the addition of aldehyde 15 (1.33 g, $3.77 \mathrm{mmol})$ and $i-\mathrm{Pr}_{2} \mathrm{NEt}(1.32 \mathrm{mml}, 7.56 \mathrm{mmol})$ in $\mathrm{CH}_{2} \mathrm{Cl}_{2}(12 \mathrm{~mL})$.

The reaction was stirred another $20 \mathrm{~min}$ and was then added saturated aqueous $\mathrm{NaHCO}_{3}(20 \mathrm{~mL})$. The aqueous phase was extracted with $\mathrm{CH}_{2} \mathrm{Cl}_{2}(3 \times 5 \mathrm{~mL})$ and the combined organic phases were washed with brine. The organic phases were dried over anhydrous $\mathrm{Na}_{2} \mathrm{SO}_{4}$, filtered, and concentrated. The residue was purified by flash chromatography (hexanes-ethyl acetate, 50:1, $\mathrm{v} / \mathrm{v})$ to provide alcohol $\mathbf{1 5 a}(1.6 \mathrm{~g}, 3.16 \mathrm{mmol}, 84 \%)$ as a colorless oil.

$\mathrm{R}_{\mathrm{f}}=0.37$ (Hexanes-Ethyl acetate, 10:1, v/v); ${ }^{1} \mathrm{H}$ NMR $\left(\mathrm{CDCl}_{3}, 400 \mathrm{MHz}\right): \delta 7.26(\mathrm{~d}, J=8.7 \mathrm{~Hz}$, 2H), $6.91(\mathrm{~d}, J=8.7 \mathrm{~Hz}, 2 \mathrm{H}), 6.45(\mathrm{~d}, J=9.5 \mathrm{~Hz}, 1 \mathrm{H}), 4.45(\mathrm{~s}, 3 \mathrm{H}), 3.83(\mathrm{~s}, 3 \mathrm{H}), 3.77(\mathrm{~m}, 1 \mathrm{H})$, $3.34(\mathrm{~m}, 1 \mathrm{H}), 2.78(\mathrm{~m}, 1 \mathrm{H}), 1.06(\mathrm{~d}, J=7.0 \mathrm{~Hz}, 2 \mathrm{H}), 0.91(\mathrm{~s}, 9 \mathrm{H}), 0.08(\mathrm{~s}, 3 \mathrm{H}), 0.07(\mathrm{~s}, 3 \mathrm{H}) ;{ }^{13} \mathrm{C}$ $\operatorname{NMR}\left(\mathrm{CDCl}_{3}, 100 \mathrm{MHz}\right): \delta 159.2,140.0,130.2,129.3,113.8,88.2,73.8,73.1,72.8,55.3,41.7$, 25.9, 18.1, 16.1, - 4.2, - 4.9; IR (neat): 2953, 1612, 1513, 1620, 1248, 1102, 1035, 837, 776; $[\alpha]_{\mathrm{D}}^{25}-11.6\left(\mathrm{c} 1.6, \mathrm{CHCl}_{3}\right)$; HRMS-ESI $(\mathrm{m} / \mathrm{z})$ calculated for $\left[\mathrm{M}+\mathrm{Na}^{+}\right]$: 529.0380, found: 529.0381.

tert-butyl(((2S,3S)-1-((4-methoxybenzyl)oxy)-3-methyl-5-(trimethylsilyl)pent-4-yn-2yl)oxy)dimethylsilane (16)

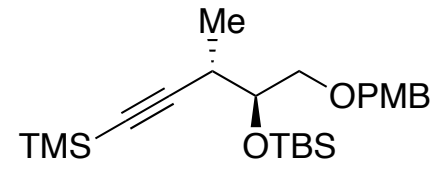

16

To a cooled $\left(-78^{\circ} \mathrm{C}\right)$ solution of $15 \mathrm{a}(1.1 \mathrm{~g}, 2.2 \mathrm{mmol})$ in THF $(20$ $\mathrm{mL})$ was added $n$-BuLi $(2.0 \mathrm{~mL}, 4.8 \mathrm{mmol}, 2.5 \mathrm{M}$ in hexane) slowly. After stirring for $30 \mathrm{~min}$, TMSCl $(0.85 \mathrm{~mL}, 6.6 \mathrm{mmol})$ was added. The mixture was allowed to stir for another $1 \mathrm{~h}$ before saturated aqueous $\mathrm{NH}_{4} \mathrm{Cl}(20 \mathrm{~mL})$ was added. The aqueous phase was extracted with diethyl ether $(3 \times 20 \mathrm{~mL})$ and the combined organic phases were washed with brine. The organic phases were dried over anhydrous $\mathrm{Na}_{2} \mathrm{SO}_{4}$, filtered, and concentrated. The residue was purified by flash chromatography (hexanes-ethyl acetate, 100:1, v/v) to provide alcohol 16 (1.0 g, $2.0 \mathrm{mmol}, 93 \%)$ as a colorless oil.

$\mathrm{R}_{\mathrm{f}}=0.37$ (Hexanes-Ethyl acetate, 10:1, v/v); ${ }^{1} \mathrm{H}$ NMR $\left(\mathrm{CDCl}_{3}, 400 \mathrm{MHz}\right): \delta 7.27(\mathrm{~d}, J=8.7 \mathrm{~Hz}$, 2H), $6.90(\mathrm{~d}, J=8.7 \mathrm{~Hz}, 2 \mathrm{H}), 4.48(\mathrm{~s}, 2 \mathrm{H}), 3.80(\mathrm{~s}, 3 \mathrm{H}), 3.77(\mathrm{~m}, 1 \mathrm{H}), 3.63(\mathrm{~m}, 1 \mathrm{~h}), 3.45(\mathrm{~m}$, 1H), 2.76 (m, 1H), 1.18 (d, J=7.0 Hz, 2H), 0.92 (s, 9H), 0.15 (s, 9H), 0.08 (s, 3H), 0.07 (s, 3H); ${ }^{13} \mathrm{C} \mathrm{NMR}\left(\mathrm{CDCl}_{3}, 100 \mathrm{MHz}\right): \delta 159.3,130.8,129.4,113.9,108.9,85.8,73.9,73.2,72.8,55.5$, 
$31.7,26.0,18.3,16.9,0.4,-4.0,-4.7$; IR (neat): 2930, 1612, 1513, 1249, 1096, 840, 776; $[\alpha]_{\mathrm{D}}^{25}-$ 14.6 (c 2.5, $\left.\mathrm{CHCl}_{3}\right)$; HRMS-ESI $(\mathrm{m} / \mathrm{z})$ calculated for $\left[\mathrm{M}+\mathrm{Na}^{+}\right]$: 443.2408, found: 443.2406.

\section{(2S,3S)-1-((4-Methoxybenzyl)oxy)-3-methyl-5-(trimethylsilyl)pent-4-yn-2-ol (17)}

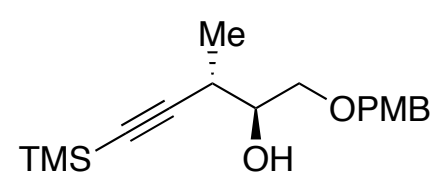

17

To a solution of $\mathbf{1 6}(0.8 \mathrm{~g}, 1.9 \mathrm{mmol})$ in $\mathrm{MeOH}(3 \mathrm{~mL})$ was added p-TsOH (36 mg, $0.2 \mathrm{mmol})$. The reaction mixture was allowed to stir for $2 \mathrm{~h}$ before $\mathrm{Et}_{3} \mathrm{~N}(0.1 \mathrm{~mL})$ was added. The volatiles were removed and the crude mixture was purified by flash chromatography (hexanes-ethyl acetate, 10:1, v/v) to provide $17(0.6 \mathrm{~g}, 1.2 \mathrm{mmol}, 90 \%)$ as a colorless oil.

$\mathrm{R}_{\mathrm{f}}=0.64$ (Hexanes-Ethyl acetate, 3:1, v/v); ${ }^{1} \mathrm{H}$ NMR $\left(\mathrm{CDCl}_{3}, 400 \mathrm{MHz}\right): \delta 7.30(\mathrm{~d}, J=8.7 \mathrm{~Hz}$, $2 \mathrm{H}), 6.91(\mathrm{~d}, J=8.7 \mathrm{~Hz}, 2 \mathrm{H}), 4.52\left(\mathrm{q}_{\mathrm{AB}}, \Delta v=5 \mathrm{~Hz}, J=12 \mathrm{~Hz}, 2 \mathrm{H}\right), 3.83(\mathrm{~s}, 3 \mathrm{H}), 3.54(\mathrm{~m}, 2 \mathrm{H})$, $2.78(\mathrm{~m}, 1 \mathrm{H}), 2.21(\mathrm{dd}, J=5.8 \mathrm{~Hz}, 0.5 \mathrm{~Hz}, 1 \mathrm{H}), 1.23(\mathrm{~d}, J=7.1 \mathrm{~Hz}, 3 \mathrm{H}), 0.16(\mathrm{~s}, 9 \mathrm{H}) ;{ }^{13} \mathrm{C}$ $\operatorname{NMR}\left(\mathrm{CDCl}_{3}, 100 \mathrm{MHz}\right): \delta 159.3,130.1,129.4,11.8,107.0,87.3,73.1,72.6,71.7,55.3,30.7$, 17.0, 0.11; IR (neat): 3446, 2957, 1612, 1514, 1249, 1082, 842, 760; $[\alpha]_{\mathrm{D}}{ }^{25}-28.3$ (c 2.6, $\mathrm{CHCl}_{3}$ ); HRMS-ESI $(\mathrm{m} / \mathrm{z})$ calculated for $\left[\mathrm{M}+\mathrm{Na}^{+}\right]$: 329.1543, found: 329.1544.

\section{((S)-3-((S)-2-(4-methoxyphenyl)-1,3-dioxolan-4-yl)but-1-yn-1-yl)trimethylsilane (18)}

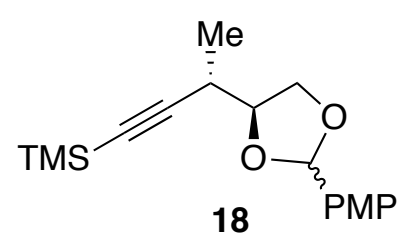
To a cooled $\left(0{ }^{\circ} \mathrm{C}\right)$ solution of $\mathrm{SM}(0.55 \mathrm{~g}, 1.8 \mathrm{mmol})$ in $\mathrm{CH}_{2} \mathrm{Cl}_{2}(30$ $\mathrm{mL})$ was added $4 \AA \mathrm{MS}(0.83 \mathrm{~g})$ and $\mathrm{DDQ}(0.6,2.7 \mathrm{mmol})$ sequentially. The reaction mixture was warmed up to ambient temperature after stirring for $30 \mathrm{~min}$ at $0{ }^{\circ} \mathrm{C}$. The reaction mixture was allowed to stir $1 \mathrm{~h}$ at ambient temperature before saturated aqueous $\mathrm{NaHCO}_{3}(20 \mathrm{~mL})$ was added. The aqueous phase was extracted with diethyl ether $(3 \times 40 \mathrm{~mL})$ and the combined organic phases were washed with brine. The organic phases were dried over anhydrous $\mathrm{Na}_{2} \mathrm{SO}_{4}$, filtered, and concentrated. The residue was purified by flash chromatography (hexanes-ethyl acetate, 10:1, $\mathrm{v} / \mathrm{v})$ to provide alcohol $18(0.46 \mathrm{~g}, 1.5 \mathrm{mmol}, 85 \%)$ as a colorless oil.

\section{(2S,3S)-2-((4-Methoxybenzyl)oxy)-3-methyl-5-(trimethylsilyl)pent-4-yn-1-ol (19)}

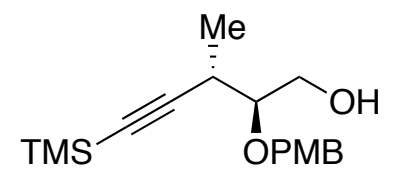

19

To a cooled $\left(-78{ }^{\circ} \mathrm{C}\right)$ solution of $\mathrm{SM}(0.15 \mathrm{~g}, 0.48 \mathrm{mmol})$ in $\mathrm{CH}_{2} \mathrm{Cl}_{2}(3$ $\mathrm{mL}$ ) was added DIBAL-H $(0.7 \mathrm{~mL}, 0.8,1 \mathrm{M}$ in toluene) slowly. The reaction was allowed to stir for $1 \mathrm{~h}$ before aqueous potassium sodium tartrate solution ( $2 \mathrm{M}, 3 \mathrm{~mL}$ ) was added slowly. The aqueous and organic phases were fully separated after stirring for $12 \mathrm{~h}$. The aqueous phase was extracted with 
diethyl ether $(3 \times 10 \mathrm{~mL})$ and the combined organic phases were washed with brine. The organic phases were dried over anhydrous $\mathrm{Na}_{2} \mathrm{SO}_{4}$, filtered, and concentrated. The residue was purified by flash chromatography (hexanes-ethyl acetate, 10:1, v/v) to provide alcohol $19(80 \mathrm{mg}, 0.26$ $\mathrm{mmol}, 58 \%)$ and $17(70 \mathrm{mg}, 0.23 \mathrm{mmol}, 42 \%)$ as a colorless oil.

$\mathrm{R}_{\mathrm{f}}=0.42$ (Hexanes-Ethyl acetate, 3:1, v/v); ${ }^{1} \mathrm{H} \mathrm{NMR}\left(\mathrm{CDCl}_{3}, 400 \mathrm{MHz}\right): \delta 7.33$ (d, J=8.6 Hz, 2H), $6.9(\mathrm{~d}, J=8.7 \mathrm{~Hz}, 2 \mathrm{H}), 4.7\left(\mathrm{q}_{\mathrm{AB}}, \Delta v=67 \mathrm{~Hz}, J=11 \mathrm{~Hz}, 2 \mathrm{H}\right), 3.83(\mathrm{~s}, 3 \mathrm{H}), 3.80(\mathrm{~m}, 1 \mathrm{H})$, $3.64(\mathrm{~m}, 1 \mathrm{H}), 3.57(\mathrm{~m}, 1 \mathrm{H}), 2.91(\mathrm{~m}, 1 \mathrm{H}), 1.93(\mathrm{br}, 1 \mathrm{H}), 1.18(\mathrm{~d}, J=7.1 \mathrm{~Hz}, 3 \mathrm{H}), 0.17(\mathrm{~s}, 9 \mathrm{H})$; ${ }^{13} \mathrm{C} \mathrm{NMR}\left(\mathrm{CDCl}_{3}, 100 \mathrm{MHz}\right): \delta 159.4,130.3,129.4,113.9,108.5,86.2,81.4,72.3,62.1,55.3$, 28.4, 15.8, 0.1; IR (neat):3446, 2957, 1514, 1249, 1082, 1037, 842, 760; $[\alpha]_{\mathrm{D}}{ }^{25}-3.3$ (c 2.0 , $\left.\mathrm{CHCl}_{3}\right)$; HRMS-ESI $(\mathrm{m} / \mathrm{z})$ calculated for $\left[\mathrm{M}+\mathrm{Na}^{+}\right]$: 329.1543 , found: 329.1542 .

\section{(2S,3S)-2-((4-Methoxybenzyl)oxy)-3-methyl-5-(trimethylsilyl)pent-4-ynal (8)}

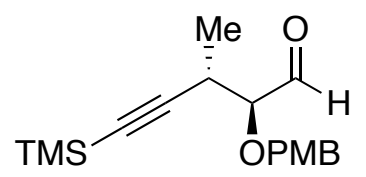

8

To a cooled $\left(0{ }^{\circ} \mathrm{C}\right)$ solution of $\mathbf{1 9}(0.26 \mathrm{~g}, 0.85 \mathrm{mmol})$ in $\mathrm{CH}_{2} \mathrm{Cl}_{2}(6 \mathrm{~mL})$ and DMSO $(2 \mathrm{~mL})$ was added $\mathrm{Et}_{3} \mathrm{~N}(0.7 \mathrm{~mL}, 5.1 \mathrm{mmol})$ and $\mathrm{SO}_{3} \bullet \mathrm{Py}$ $(0.58 \mathrm{~g}, 3.7 \mathrm{mmol})$ sequentially. The reaction mixture was allowed to stir $5 \mathrm{~min}$ before saturated aqueous $\mathrm{NH}_{4} \mathrm{Cl}(10 \mathrm{~mL})$ and diethyl ether $(10$

$\mathrm{mL})$ was added. The aqueous phase was extracted with diethyl ether $(3 \times 10 \mathrm{~mL})$ and the combined organic phases were washed with brine. The organic phases were dried over anhydrous $\mathrm{Na}_{2} \mathrm{SO}_{4}$, filtered, and concentrated. The residue was purified by flash chromatography (hexanesethyl acetate, $20: 1, \mathrm{v} / \mathrm{v})$ to provide $8(0.25 \mathrm{~g}, 0.82 \mathrm{mmol}, 96 \%)$ as a colorless oil.

$\mathrm{R}_{\mathrm{f}}=0.65$ (Hexanes-Ethyl acetate, 3:1, v/v); ${ }^{1} \mathrm{H} \mathrm{NMR}\left(\mathrm{CDCl}_{3}, 400 \mathrm{MHz}\right): \delta 9.73(\mathrm{~d}, J=2.0 \mathrm{~Hz}$, $1 \mathrm{H}), 7.31(\mathrm{~d}, J=8.6 \mathrm{~Hz}, 2 \mathrm{H}), 6.9(\mathrm{~d}, J=8.6 \mathrm{~Hz}, 2 \mathrm{H}), 4.68\left(\mathrm{q}_{\mathrm{AB}}, \Delta v=53 \mathrm{~Hz}, J=12 \mathrm{~Hz}, 2 \mathrm{H}\right), 3.83$ (s, 3H), $3.76(\mathrm{dd}, J=5.5 \mathrm{~Hz}, 2.0 \mathrm{~Hz}, 1 \mathrm{H}), 2.94(\mathrm{~m}, 1 \mathrm{H}), 1.21$ (d, $J=7.1 \mathrm{~Hz}, 3 \mathrm{H}), 0.17$ (s, 9H); ${ }^{13} \mathrm{C} \mathrm{NMR}\left(\mathrm{CDCl}_{3}, 100 \mathrm{MHz}\right): \delta 202.3,159.6,129.7,129.2,113.9,105.8,87.5,84.0,72.5,55.3$, 28.8, 16.3, 0; IR (neat): 2954, 2357, 1731, 1515, 1250, 1110, 830; $[\alpha]_{\mathrm{D}}{ }^{25}+12.4\left(\mathrm{c} 0.5, \mathrm{CHCl}_{3}\right)$; HRMS-ESI $(m / z)$ calculated for $\left[\mathrm{M}+\mathrm{Na}^{+}\right]$: 327.1387 , found: 327.1385 .

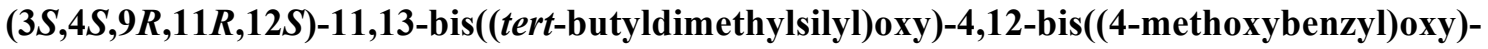

\section{3,9-dimethyl-1-(trimethylsilyl)trideca-1,6-diyn-5-ol (21)}

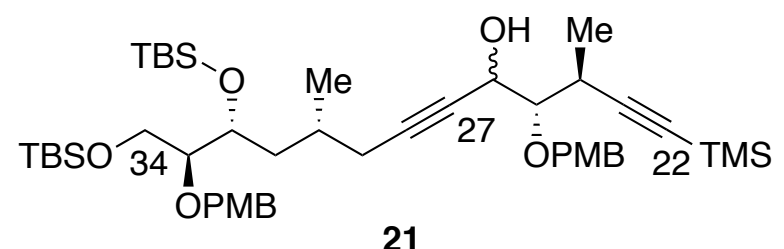

21
To a flask of $\mathrm{CrCl}_{2}(0.5 \mathrm{~g}, 4.1 \mathrm{mmol})$ and $\mathrm{NiCl}_{2}(1.3 \mathrm{mg}, 0.4 \mathrm{mmol})$ was added the solution of alkynyl iodide $\mathbf{2 0}^{3}$ (0.65 g, 1 $\mathrm{mmol})$ and aldehyde $8(0.25 \mathrm{~g}, 0.82 \mathrm{mmol})$ in THF ( $5 \mathrm{~mL})$. The reaction was allowed to stir 
$14 \mathrm{~h}$ before $1 \mathrm{M}$ aqueous serine saturated with $\mathrm{NaHCO}_{3}(20 \mathrm{~mL})$ and diethyl ether $(20 \mathrm{~mL})$ was added. The mixture was stirred for $2 \mathrm{~h}$ to fully separate the aqueous and organic phases. The aqueous phase was then extracted with diethyl ether $(3 \times 30 \mathrm{~mL})$ and the combined organic phases were washed with brine. The residue was purified by flash chromatography (hexanes-ethyl acetate, 60:1 to 20:1, v/v) to provide alcohol $21(0.64 \mathrm{~g}, 0.77 \mathrm{mmol}, 95 \%)$ as a colorless oil.

(2S,3R,5R,10S,11S)-3-((tert-butyldimethylsilyl)oxy)-2,10-bis((4-methoxybenzyl)oxy)-5,11dimethyl-13-(trimethylsilyl)trideca-7,12-diyne-1,9-diol (21a)

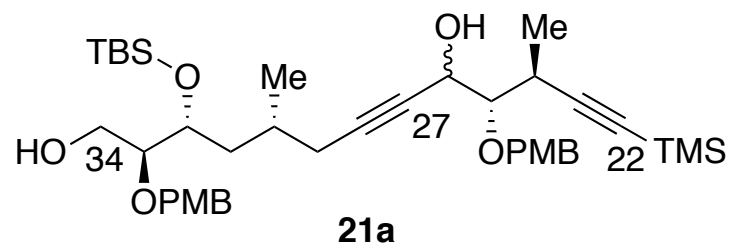

To a solution of $\mathbf{2 0}(0.51 \mathrm{~g}, 0.62 \mathrm{mmol})$ in THF $(6 \mathrm{~mL})$ was added pyridine $(0.2 \mathrm{~mL}, 2.8 \mathrm{mmol})$ and $\mathrm{HF} \bullet \mathrm{Py}(0.1 \mathrm{~mL}, 0.93 \mathrm{mmol})$ sequentially. The mixture was stirred for $12 \mathrm{~h}$ before saturated aqueous $\mathrm{NaHCO}_{3}(10 \mathrm{~mL})$ was slowly added. The aqueous phase was then extracted with diethyl ether $(3 \times 10 \mathrm{~mL})$ and the combined organic phases were washed with brine. The residue was purified by flash chromatography (hexanes-ethyl acetate, $8: 1, \mathrm{v} / \mathrm{v}$ ) to provide alcohol 21a (0.42 g, $0.6 \mathrm{mmol}, 97 \%)$ as a colorless oil.

\section{(2R,3R,5R,10S,11S)-3-((tert-Butyldimethylsilyl)oxy)-2,10-bis((4-methoxybenzyl)oxy)-5,11-} dimethyl-9-oxo-13-(trimethylsilyl)trideca-7,12-diynal (22)

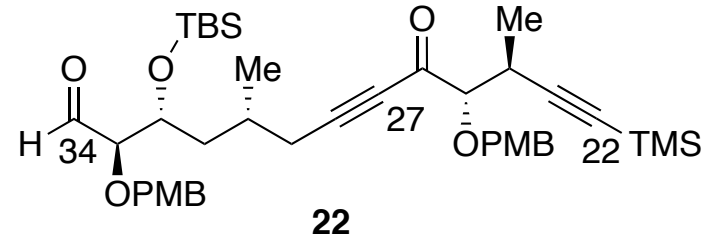

To a solution of $21 \mathrm{a}(0.42 \mathrm{~g}, 0.6 \mathrm{mmol})$ in $\mathrm{CH}_{2} \mathrm{Cl}_{2}(6 \mathrm{~mL})$ and DMSO $(3 \mathrm{~mL})$ was added $i$ $\mathrm{Pr}_{2} \mathrm{NEt}(1.2 \mathrm{~mL}, 7.2 \mathrm{mmol})$ and $\mathrm{SO}_{3} \bullet \mathrm{Py}(0.74 \mathrm{~g}$, $4.8 \mathrm{mmol})$ sequentially. The mixture was stirred 10 min before saturated aqueous $\mathrm{NH}_{4} \mathrm{Cl}(10 \mathrm{~mL})$ was added. The aqueous phase was then extracted with diethyl ether $(3 \times 10 \mathrm{~mL})$ and the combined organic phases were washed with brine. The residue was purified by flash chromatography (hexanes-ethyl acetate, $8: 1, \mathrm{v} / \mathrm{v}$ ) to provide aldehyde $22(0.4 \mathrm{~g}, 0.57 \mathrm{mmol}, 95 \%)$ as a colorless oil.

$\mathrm{R}_{\mathrm{f}}=0.65\left(\right.$ Hexanes-Ethyl acetate, 5:1, v/v); ); ${ }^{1} \mathrm{H} \mathrm{NMR}\left(\mathrm{CDCl}_{3}, 400 \mathrm{MHz}\right): \delta 9.63(\mathrm{~d}, J=1.8 \mathrm{~Hz}$, $1 \mathrm{H}), 7.31(\mathrm{~m}, 4 \mathrm{H}), 6.87(\mathrm{~m}, 4 \mathrm{H}), 4.76\left(\mathrm{q}_{\mathrm{AB}}, \Delta v=125 \mathrm{~Hz}, J=9.4 \mathrm{~Hz}, 2 \mathrm{H}\right), 4.57\left(\mathrm{q}_{\mathrm{AB}}, \Delta v=7 \mathrm{~Hz}, J\right.$ $=9.2 \mathrm{~Hz}, 2 \mathrm{H}), 4.07(\mathrm{~m}, 1 \mathrm{H}), 3.82(\mathrm{~s}, 3 \mathrm{H}), 3.81(\mathrm{~s}, 3 \mathrm{H}), 3.71(\mathrm{~d}, J=5.9 \mathrm{~Hz}, 1 \mathrm{H}), 3.65(\mathrm{t}, J=2$ Hz, 1H), $3.04(\mathrm{~m}, 1 \mathrm{H}), 2.43(\mathrm{~m}, 1 \mathrm{H}), 2.26(\mathrm{~m}, 1 \mathrm{H}), 1.88(\mathrm{~m}, 1 \mathrm{H}), 1.57(\mathrm{~m}, 2 \mathrm{H}), 1.17(\mathrm{~d}, J=5.6$ $\mathrm{Hz}, 3 \mathrm{H}), 1.04(\mathrm{~d}, J=5.4 \mathrm{~Hz}, 3 \mathrm{H}), 0.88(\mathrm{~s}, 9 \mathrm{H}), 0.17(\mathrm{~s}, 9 \mathrm{H}), 0.1(\mathrm{~s}, 3 \mathrm{H}), 0.08(\mathrm{~s}, 3 \mathrm{H}) ;{ }^{13} \mathrm{C}$ $\mathrm{NMR}\left(\mathrm{CDCl}_{3}, 100 \mathrm{MHz}\right): \delta 203.4,187.6,159.5,159.4,129.72,129.69,129.26,129.23,113.91$, $113.72,106.7,95.9,86.5,86.1,80.6,72.6,72.3,72.0,55.3,55.2,40.2,30.1,28.3,26.1,25.8$, 
$20.2,18.1,16.8,0.1,-4.4,-4.8$; IR (neat): $2924,1725,1612,1513,1462,1248,1098,840 ;[\alpha]_{\mathrm{D}}^{25}$ $+6.6\left(\mathrm{c} 0.5, \mathrm{CHCl}_{3}\right)$; HRMS-ESI $(\mathrm{m} / z)$ calculated for $\left[\mathrm{M}+\mathrm{Na}^{+}\right]$: 729.3613, found: 729.3605 .

\section{(3S,4S,9R,11R,12S,13R,16S,18R)-19-Azido-11-((tert-butyldimethylsilyl)oxy)-13-hydroxy-} 4,12-bis((4-methoxybenzyl)oxy)-3,9,16,18-tetramethyl-1-(trimethylsilyl)nonadeca-1,6-diyne5,15-dione (22a)

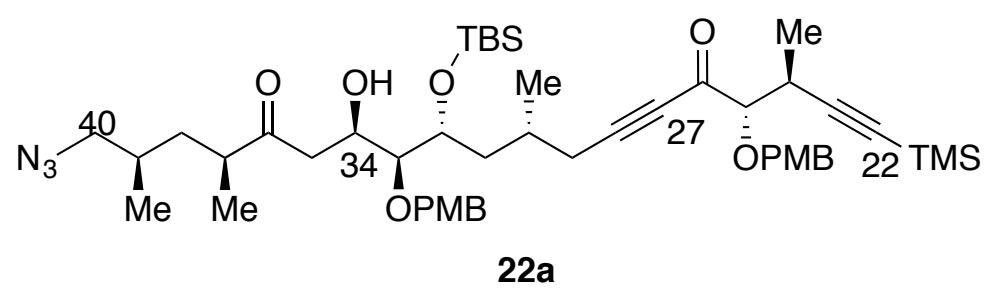

To a flask of $\mathrm{MgBr}_{2} \cdot \mathrm{OEt}_{2}(0.55$ $\mathrm{g}, 2.13 \mathrm{mmol})$ was added the solution of $9 \quad(0.15 \mathrm{~g}, \quad 0.21$ mmol) in $\mathrm{CH}_{2} \mathrm{Cl}_{2}(5 \mathrm{~mL})$ at -78 ${ }^{\circ} \mathrm{C}$. After stirring $15 \mathrm{~min}$, the

mixture was added solution of silyl enol ether $(0.3 \mathrm{~g}, 1.25 \mathrm{mmol})$ in $\mathrm{CH}_{2} \mathrm{Cl}_{2}(4 \mathrm{~mL})$. The reaction was allowed to stir for $5 \mathrm{~h}$, before slowly warming up to $-40{ }^{\circ} \mathrm{C}$ in $1 \mathrm{~h}$. $\mathrm{pH}=7$ aqueous buffer (10 $\mathrm{mL})$ and diethyl ether $(10 \mathrm{~mL})$ was added. The aqueous phase was then extracted with diethyl ether $(3 \times 10 \mathrm{~mL})$ and the combined organic phases were washed with brine. The residue was purified by flash chromatography (hexanes-ethyl acetate, $10: 1, \mathrm{v} / \mathrm{v})$ to provide alcohol $22(0.16 \mathrm{~g}$, $0.18 \mathrm{mmol}, 88 \%$ ) as a colorless oil.

$\mathrm{R}_{\mathrm{f}}=0.6$ (Hexanes-Ethyl acetate, 3:1, v/v); ${ }^{1} \mathrm{H}$ NMR $\left(\mathrm{CDCl}_{3}, 400 \mathrm{MHz}\right): \delta 7.33(\mathrm{~d}, J=8.7 \mathrm{~Hz}$, 2H), $7.26(\mathrm{~d}, J=8.7 \mathrm{~Hz}, 2 \mathrm{H}), 6.9(\mathrm{~m}, 4 \mathrm{H}), 4.72(\mathrm{~m}, 2 \mathrm{H}), 4.45(\mathrm{~m}, 2 \mathrm{H}), 4.34(\mathrm{~m}, 1 \mathrm{H}), 4.09$ (m, $1 \mathrm{H}), 3.91(\mathrm{~m}, 6 \mathrm{H}), 3.72(\mathrm{~d}, J=7.4 \mathrm{~Hz}, 2 \mathrm{H}), 3.57(\mathrm{~d}, J=2.5 \mathrm{~Hz}, 1 \mathrm{H}), 3.32(\mathrm{t}, J=2.4 \mathrm{~Hz}, 1 \mathrm{H}), 3.2$ (m, 1H), $3.08(\mathrm{~m}, 2 \mathrm{H}), 2.77(\mathrm{~m}, 1 \mathrm{H}), 2.54(\mathrm{~m}, 3 \mathrm{H}), 2.27(\mathrm{~m}, 1 \mathrm{H}), 1.95(\mathrm{~m}, 1 \mathrm{H}), 1.76(\mathrm{~m}, 2 \mathrm{H})$, $1.61(\mathrm{~m}, 2 \mathrm{H}), 1.17$ (d, $J=7 \mathrm{~Hz}, 3 \mathrm{H}), 1.07$ (m, 7H), 0.94 (d, $J=6.6 \mathrm{~Hz}, 3 \mathrm{H}), 0.91$ (s, 9H), 0.17 (s, $9 \mathrm{H}), 0.15(\mathrm{~s}, 3 \mathrm{H}), 0.11(\mathrm{~s}, 3 \mathrm{H}) ;{ }^{13} \mathrm{C} \mathrm{NMR}\left(\mathrm{CDCl}_{3}, 100 \mathrm{MHz}\right): \delta 213.0,187.5,159.4,130.0$, $129.69,129.66,129.26,113.9,113.7,106.7,95.9,86.44,86.34,80.7,80.5,72.6,72.3,72.0,67.0$, $57.5,55.24,55.23,44.6,44.3,40.6,37.1,31.4,30.1,28.6,26.6,25.8,20.1,18.0,17.9,17.0,16.8$, $0.1,-4.3,-4.7$; IR (neat): 3447, 2956, 2098, 1674, 1514, 1462, 1249, 842, 759; $[\alpha]_{\mathrm{D}}^{25}-24.9$ (c 1.0, $\left.\mathrm{CHCl}_{3}\right)$; HRMS-ESI $(\mathrm{m} / \mathrm{z})$ calculated for $\left[\mathrm{M}+\mathrm{Na}^{+}\right]$: 898.4828, found: 898.4813 . 
(3S,4S,9R,11R,12R,13R,16S,18R)-19-azido-11-((tert-butyldimethylsilyl)oxy)-4,12-bis((4methoxybenzyl)oxy)-3,9,16,18-tetramethyl-13-((triethylsilyl)oxy)-1-

(trimethylsilyl)nonadeca-1,6-diyne-5,15-dione (23)

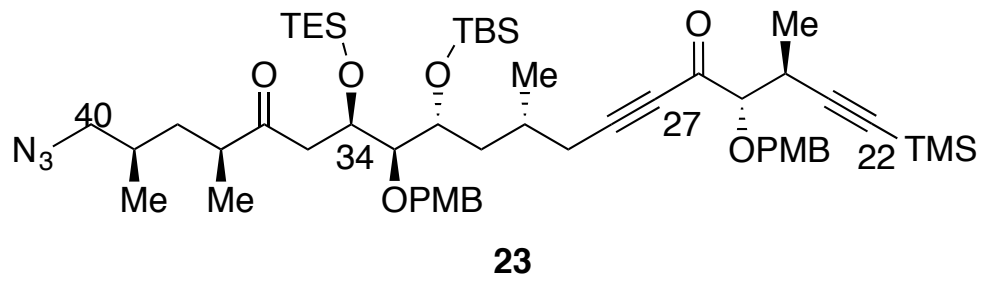

To a cooled $\left(-55^{\circ} \mathrm{C}\right)$ solution of $22 \mathrm{a}(0.23 \mathrm{~g}, 0.26 \mathrm{mmol})$ in $\mathrm{CH}_{2} \mathrm{Cl}_{2}(2 \mathrm{~mL})$ was added 2,6lutidine $(0.12 \mathrm{~mL}, 1.0 \mathrm{mmol})$, TESOTf $(0.15 \mathrm{~mL}, 0.65 \mathrm{mmol})$

successively. The reaction mixture was allowed to stir $20 \mathrm{~min}$ before $\mathrm{pH}=7$ aqueous buffer ( 5 $\mathrm{mL}$ ) and diethyl ether $(5 \mathrm{~mL})$ was added. The aqueous phase was then extracted with diethyl ether $(3 \times 10 \mathrm{~mL})$ and the combined organic phases were washed with brine. The residue was purified by flash chromatography (hexanes-ethyl acetate, 30:1, v/v) to provide alcohol $23(0.25 \mathrm{~g}$, $0.25 \mathrm{mmol}, 95 \%)$ as a colorless oil.

$\mathrm{R}_{\mathrm{f}}=0.65$ (Hexanes-Ethyl acetate, 3:1, v/v); ${ }^{1} \mathrm{H} \mathrm{NMR}\left(\mathrm{CDCl}_{3}, 400 \mathrm{MHz}\right): \delta 7.33(\mathrm{~d}, J=8.7 \mathrm{~Hz}$, 2H), $7.25(\mathrm{~d}, J=8.7 \mathrm{~Hz}, 2 \mathrm{H}), 6.9(\mathrm{~d}, J=8.7 \mathrm{~Hz}, 4 \mathrm{H}), 4.78\left(\mathrm{q}_{\mathrm{AB}}, \Delta v=132 \mathrm{~Hz}, J=11.6 \mathrm{~Hz}, 2 \mathrm{H}\right)$, $4.78\left(\mathrm{q}_{\mathrm{AB}}, \Delta v=67 \mathrm{~Hz}, J=11.4 \mathrm{~Hz}, 2 \mathrm{H}\right), 4.40(\mathrm{~m}, 1 \mathrm{H}), 3.98(\mathrm{~m}, 1 \mathrm{H}), 3.81(\mathrm{~m}, 6 \mathrm{H}), 3.72(\mathrm{~d},, J=$ $7.5 \mathrm{~Hz}, 2 \mathrm{H}), 3.48(\mathrm{dd}, J=5.9 \mathrm{~Hz}, 1.8 \mathrm{~Hz}, 1 \mathrm{H}), 3.21(\mathrm{~m}, 1 \mathrm{H}), 3.06(\mathrm{~m}, 2 \mathrm{H}), 2.85(\mathrm{~m}, 1 \mathrm{H}), 2.72(\mathrm{~m}$, 1H), $2.72(\mathrm{~m}, 1 \mathrm{H}), 2.61(\mathrm{~m}, 1 \mathrm{H}), 2.51(\mathrm{~m}, 1 \mathrm{H}), 2.23(\mathrm{~m}, 1 \mathrm{H}), 2.01(\mathrm{~m}, 1 \mathrm{H}), 1.78(\mathrm{~m}, 3 \mathrm{H}), 1.51$ (m, 1H), $1.17(\mathrm{~d}, J=7 \mathrm{~Hz}, 3 \mathrm{H}), 1.07(\mathrm{~m}, 7 \mathrm{H}), 0.92(\mathrm{~m}, 21 \mathrm{H}), 0.58(\mathrm{~m}, 6 \mathrm{H}), 0.17(\mathrm{~s}, 9 \mathrm{H}), 0.11(\mathrm{~s}$, $3 \mathrm{H}), 0.09$ (s, 3H); ${ }^{13} \mathrm{C} \mathrm{NMR}\left(\mathrm{CDCl}_{3}, 100 \mathrm{MHz}\right): \delta 212.0,187.4,159.4,159.1,130.9,129.7,129.3$, $129.1,113.7,113.6,106.7,96.6,86.5,86.3,84.0,80.4,73.0,72.3,71.5,68.5,57.6,55.23,55.22$, $45.5,44.3,39.9,36.9,31.4,30.1,28.7,26.0,25.6,20.7,18.1,18.0,17.0,16.8,7.0,4.9,0.1$, - 3.6, - 4.9; IR (neat): 2953, 1710, 1667, 1457, 1248, 1074, 836, 735; $[\alpha]_{\mathrm{D}}^{25}-7.3$ (c 1.0, $\left.\mathrm{CHCl}_{3}\right)$; HRMS-ESI $(\mathrm{m} / \mathrm{z})$ calculated for $\left[\mathrm{M}+\mathrm{Na}^{+}\right]$: 1012.5693, found: 1012.5689 .

\section{$(3 S, 4 S, 9 R, 11 R, 12 R, 13 R, 16 S, 18 R)-19$-azido-11-((tert-butyldimethylsilyl)oxy)-4,12-bis((4-} methoxybenzyl)oxy)-3,9,16,18-tetramethyl-13-((triethylsilyl)oxy)-1-

(trimethylsilyl)nonadeca-1,6-diyne-5,15-dione (7)

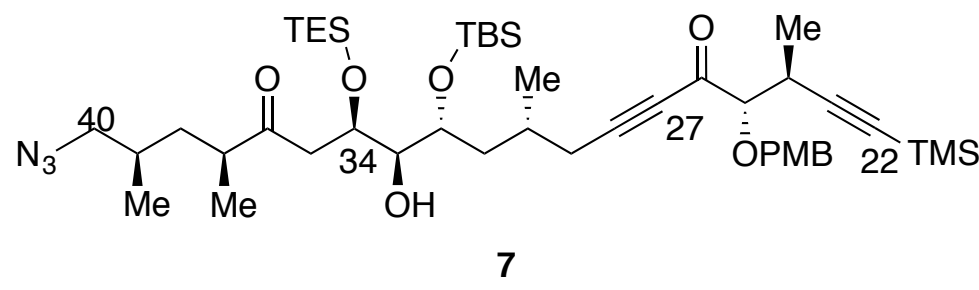

To a solution of $23(0.11 \mathrm{~g}$, $0.11 \mathrm{mmol})$ in $\mathrm{CH}_{2} \mathrm{Cl}_{2}(2 \mathrm{~mL})$, $\mathrm{pH}=7$ aqueous buffer $(0.4 \mathrm{~mL})$ and $t-\mathrm{BuOH} \quad(0.2 \mathrm{~mL})$ was added DDQ (100 mg, 0.44

$\mathrm{mmol})$. The reaction was allowed to stir for $10 \mathrm{~min}$ before $\mathrm{pH}=7$ aqueous buffer $(4 \mathrm{~mL})$ and 
diethyl ether $(8 \mathrm{~mL})$ was added. The aqueous phase was then extracted by diethyl ether $(3 \times 8$ $\mathrm{mL}$ ) and the combined organic phases were washed with brine. The residue was purified by flash chromatography (hexanes-ethyl acetate, 20:1, v/v) to provide alcohol $6(0.1 \mathrm{~g}, 0.11 \mathrm{mmol}, 99 \%)$ as a colorless oil.

\section{$(3 S, 4 S, 8 S, 10 R)-10-((2 R, 3 R)-5-((2 S, 4 R)-5$-azido-4-methylpentan-2-yl)-5-methoxy-3-}

((triethylsilyl)oxy)tetrahydrofuran-2-yl)-10-((tert-butyldimethylsilyl)oxy)-4-((4methoxybenzyl)oxy)-3,8-dimethyl-1-(trimethylsilyl)deca-1,6-diyn-5-one (24)

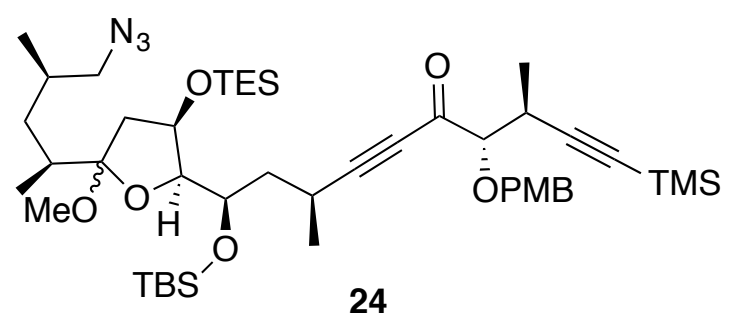

with diethyl ether $(3 \times 5 \mathrm{~mL})$ and the combined organic phases were washed with brine. The residue was purified by flash chromatography (hexanes-ethyl acetate, 15:1, v/v) to provide alcohol 24 (0.1 g, $0.11 \mathrm{mmol}, 99 \%)$ as a colorless oil.

(3S,4S)-1-((3aR,5S,7S,9R,9aR)-2-((2S,4R)-5-Azido-4-methylpentan-2-yl)-2-methoxy-7methyloctahydro-5H-5,9-epoxyfuro[3,2-b]oxocin-5-yl)-3-((4-methoxybenzyl)oxy)-4methylhex-5-yn-2-one (25)

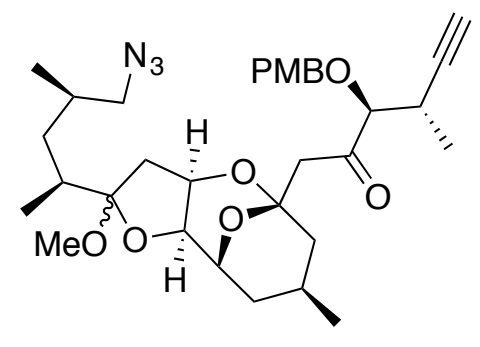

25 (1.5 mmol) was added PPTS (3 $\mathrm{mg}, 1.1 \mu \mathrm{mol})$. The reaction was stirred for $10 \mathrm{~min}$ at ambient temperature. To the reaction mixture was added $\mathrm{pH}=7$ aqueous buffer $(5 \mathrm{~mL})$ and diethyl ether $(3 \mathrm{~mL})$. The aqueous phase was then extracted

To a solution of $7(0.11 \mathrm{~g}, 0.11 \mathrm{mmol})$ in $\mathrm{MeOH}$ 
$(\mathrm{d}, J=6.7 \mathrm{~Hz}, 3 \mathrm{H}), 0.84(\mathrm{~m}, 4 \mathrm{H}), 0.71(\mathrm{~d}, J=6.7 \mathrm{~Hz}, 3 \mathrm{H}) ;{ }^{13} \mathrm{C} \mathrm{NMR}\left(\mathrm{C}_{6} \mathrm{D}_{6}, 100 \mathrm{MHz}\right): 206.0$, 160.0, 130.3, 129.9, 114.1, 113.4, 96.2, 87.4, 85.1, 75.8, 73.7, 73.0, 71.0, 70.1, 56.7, 54.8, 50.9, $47.8,43.0,41.6,36.6,35.0,33.5,31.3,29.3,25.2,23.3,19.6,17.5,15.4$; IR (neat) $v_{\max } 3289$, $2939,2089,1717,1582,1500,1448,1240,1046,822 \mathrm{~cm}^{-1} ;[\alpha]_{\mathrm{D}}^{25}=-15.0$ (c 0.5 , benzene); HRMS-ESI $(\mathrm{m} / \mathrm{z})$ calculated for [M+ $\left.\mathrm{Na}^{+}\right]$: 606.3150 , found: 606.3145 .

2-(trimethylsilyl)ethyl ((2R,4S)-4-((3a $R, 5 S, 7 S, 9 R, 9 \mathrm{a} R)-2-$ methoxy-5-((3S,4S)-3-((4methoxybenzyl)oxy)-4-methyl-2-oxohex-5-yn-1-yl)-7-methyloctahydro-2H-5,9epoxyfuro[3,2-b]oxocin-2-yl)-2-methylpentyl)carbamate (25b)

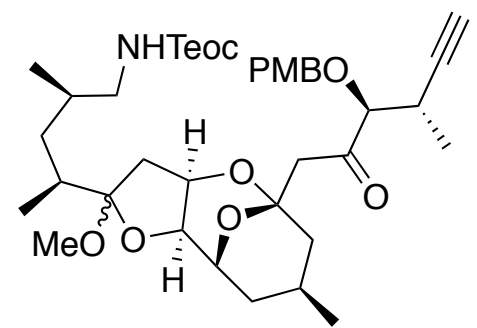

25b

To a solution of $25(30 \mathrm{mg}, 52 \mu \mathrm{mol})$ in $\mathrm{MeCN}(0.5 \mathrm{~mL})$ and $\mathrm{MeOH}(0.5 \mathrm{~mL})$ was added $\mathrm{Ph}_{3} \mathrm{P}(36 \mathrm{mg}, 0.13 \mathrm{mmol})$. The mixture was stirred for $12 \mathrm{~h}$ before TeocOSu (49 mg, 0.18 mmol) was added. After another $12 \mathrm{~h}$, the reaction mixture was concentrated. The residue was purified by flash chromatography (hexanes-ethyl acetate- $\mathrm{Et}_{3} \mathrm{~N}, 3: 1: 0.03, \mathrm{v} / \mathrm{v} / \mathrm{v}$ ) to provide $29 \mathrm{mg}$ crude product $\mathbf{2 5 b}$.

2-(trimethylsilyl)ethyl $((2 R, 4 S)-4-((3 \mathrm{a} R, 5 S, 7 S, 9 R, 9 \mathrm{a} R)-2-m e t h o x y-5-((3 S, 4 S)-3-((4-$ methoxybenzyl)oxy)-4-methyl-2-methylenehex-5-yn-1-yl)-7-methyloctahydro-2H-5,9epoxyfuro[3,2-b]oxocin-2-yl)-2-methylpentyl)carbamate (26)

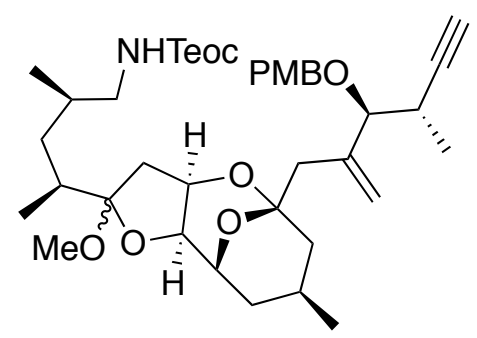

26

To a stirred suspension of methyl triphenylphosphonium iodide $(0.2 \mathrm{~g}, 0.50 \mathrm{mmol})$ in PhMe $(1 \mathrm{~mL})$ was added KHMDS $(0.8 \mathrm{~mL}$, $0.45 \mathrm{mmol}, 0.5 \mathrm{M}$ solution in $\mathrm{PhMe}$ ) at ambient temperature. The mixture was heated to $80{ }^{\circ} \mathrm{C}$. After stirring for $30 \mathrm{~min}$, the yellow solution was allowed to slowly cool to ambient temperature. The resulting solution was added to a solution of 25b in toluene $(1 \mathrm{~mL})$. The solution was stirred at this temperature for $30 \mathrm{~min}$, before $\mathrm{pH}=7$ aqueous buffer $(1 \mathrm{~mL})$ and diethyl ether $(2 \mathrm{~mL})$ was added. The aqueous phase was then extracted with diethyl ether $(3 \times 3 \mathrm{~mL})$ and the combined organic phases were washed with brine. The residue was purified by flash chromatography (hexanes-ethyl acetate-Et $\left.{ }_{3} \mathrm{~N}, 4: 1: 0.02, \mathrm{v} / \mathrm{v} / \mathrm{v}\right)$ to provide 26 (20 mg, $29 \mu \mathrm{mol}, 55 \%$ for 2 steps) as a colorless oil 
$\mathrm{R}_{\mathrm{f}}=0.55$ (hexane : ethyl acetate, $2: 1$, v/v); ${ }^{1} \mathrm{H}$ NMR $\left(\mathrm{C}_{6} \mathrm{D}_{6}, 400 \mathrm{MHz}\right) \delta 7.37(\mathrm{~d}, J=8.5 \mathrm{~Hz}$, $2 \mathrm{H}), 6.82(\mathrm{~d}, J=8.5 \mathrm{~Hz}, 2 \mathrm{H}), 5.53(\mathrm{~d}, \mathrm{~J}=2.0 \mathrm{~Hz}, 1 \mathrm{H}), 5.42(\mathrm{~s}, 1 \mathrm{H}), 4.67\left(\mathrm{q}_{\mathrm{AB}}, \Delta v=112 \mathrm{~Hz}, J=12.0\right.$ $\mathrm{Hz}, 1 \mathrm{H}), 4.55(\mathrm{~m}, 1 \mathrm{H}), 4.40(\mathrm{~m}, 2 \mathrm{H}), 4.30(\mathrm{~m}, 3 \mathrm{H}), 4.07$ (d, $J=6.0 \mathrm{~Hz}, 1 \mathrm{H}), 3.39$ (d, $J=4.0 \mathrm{~Hz}$, $1 \mathrm{H}), 3.32(\mathrm{~s}, 4 \mathrm{H}), 3.16(\mathrm{~s}, 3 \mathrm{H}), 2.93(\mathrm{~m}, 2 \mathrm{H}), 2.53\left(\mathrm{q}_{\mathrm{AB}}, \Delta v=42 \mathrm{~Hz}, J=14.5 \mathrm{~Hz}, 2 \mathrm{H}\right), 2.26(\mathrm{~m}$, 1H), 2.09 (m, 2H), 1.96 (d, J=2.5 Hz, 1H), 1.73 (m, 4H), 1.49 (m, 1H), 1.31 (d, J=7.0 Hz, 3H), $1.16(\mathrm{~d}, J=7.0 \mathrm{~Hz}, 3 \mathrm{H}), 1.00(\mathrm{~m}, 3 \mathrm{H}), 0.87(\mathrm{~m}, 5 \mathrm{H}), 0.71(\mathrm{~d}, J=7.0 \mathrm{~Hz}, 3 \mathrm{H}),-0.05(\mathrm{~s}, 9 \mathrm{H}) ;{ }^{13} \mathrm{C}$ $\operatorname{NMR}\left(\mathrm{C}_{6} \mathrm{D}_{6}, 100 \mathrm{MHz}\right) \delta 161.1,158.4,143.9,133.0,130.9,130.1,119.0,115.5,113.1,98.4$, 88.0, 85.9, 77.7, 75.0, 72.3, 71.6, 64.1, 56.2, 49.4, 47.1, 44.0, 42.1, 38.4, 36.5, 36.1, 33.2, 32.2, 26.9, 24.9, 24.5, 21.2, 19.6, 17.2, 15.8, 0.0; IR (neat) $v_{\max } 3399,2949,2359,1711,1507,1458$, 1244, 1130, 1040, $843 \mathrm{~cm}^{-1} ;[\alpha]_{\mathrm{D}}^{25}=+10.0$ (c 0.2 , benzene); HRMS-ESI $(\mathrm{m} / \mathrm{z})$ calculated for $\left[\mathrm{M}+\mathrm{Na}^{+}\right]:$722.4059, found: 722.4055 .

(2S,3aR,3'S,5S,5'R,7S,9R,9aR)-2-(trimethylsilyl)ethyl 5-((3S,4S)-3-((4-methoxybenzyl)oxy)4-methyl-2-methylenehex-5-yn-1-yl)-3',5',7-trimethyloctahydrospiro[5,9-epoxyfuro[3,2-

b]oxocine-2,2'-piperidine]-1'-carboxylate (6)

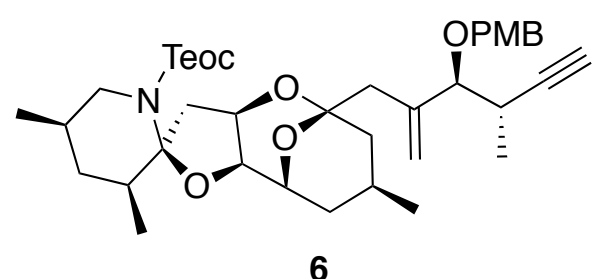

To a solution of $26(5 \mathrm{mg}, 7 \mu \mathrm{mol})$ in $\mathrm{MeCN}(0.5 \mathrm{~mL})$ was added $\mathrm{Nd}(\mathrm{OTf})_{3}(0.1 \mathrm{mg})$. The reaction was allowed to stir for $5 \mathrm{~min}$ before $\mathrm{Et}_{3} \mathrm{~N}(0.01 \mathrm{~mL})$ was added. The mixture directly filtered through a pad of silica gel and the pad was washed with ethyl acetate $(3 \mathrm{~mL})$. The combined organic phase was concentrated. The residue was purified by flash chromatography (hexanes-ethyl acetate- $\left.\mathrm{Et}_{3} \mathrm{~N}, 15: 1: 0.08, \mathrm{v} / \mathrm{v} / \mathrm{v}\right)$ to provide $6(3.5 \mathrm{mg}, 5 \mu \mathrm{mol}, 71 \%$ ) as a colorless oil.

$\mathrm{R}_{\mathrm{f}}=0.45$ (hexane : ethyl acetate, $\left.3: 1, \mathrm{v} / \mathrm{v}\right) ;{ }^{1} \mathrm{H} \mathrm{NMR}\left(\mathrm{C}_{6} \mathrm{D}_{6}, 400 \mathrm{MHz}\right) \delta 7.39(\mathrm{~d}, J=8.5 \mathrm{~Hz}, 2 \mathrm{H})$, $6.82(\mathrm{~d}, J=8.5 \mathrm{~Hz}, 2 \mathrm{H}), 5.62(\mathrm{~m}, 1 \mathrm{H}), 5.37(\mathrm{~d}, J=2.0 \mathrm{~Hz}, 1 \mathrm{H}), 4.57\left(\mathrm{q}_{\mathrm{AB}}, \Delta v=135 \mathrm{~Hz}, J=12.0 \mathrm{~Hz}\right.$, $2 \mathrm{H}), 4.33(\mathrm{~m}, 3 \mathrm{H}), 4.25(\mathrm{~m}, 1 \mathrm{H}), 4.20(\mathrm{~d}, J=4.5 \mathrm{~Hz}, 1 \mathrm{H}), 4.15(\mathrm{~m}, 1 \mathrm{H}), 4.02(\mathrm{dd}, J=12.5 \mathrm{~Hz}$, $4.0 \mathrm{~Hz}, 1 \mathrm{H}), 3.45$ (t, $J=12.5 \mathrm{~Hz}, 1 \mathrm{H}), 3.31(\mathrm{~s}, 3 \mathrm{H}), 3.17(\mathrm{~m}, 2 \mathrm{H}), 2.56\left(\mathrm{q}_{\mathrm{AB}}, \Delta v=54 \mathrm{~Hz}, J=14.5 \mathrm{~Hz}\right.$, $2 \mathrm{H}), 2.24(\mathrm{~m}, 1 \mathrm{H}), 1.98(\mathrm{~m}, 2 \mathrm{H}), 1.72(\mathrm{~m}, 3 \mathrm{H}), 1.47(\mathrm{~m}, 2 \mathrm{H}), 1.19(\mathrm{~m}, 3 \mathrm{H}), 1.12(\mathrm{~m}, 2 \mathrm{H}), 0.82(\mathrm{~d}$, $J=7.0 \mathrm{~Hz}, 6 \mathrm{H}), 0.74(\mathrm{~d}, J=6.5 \mathrm{~Hz}, 3 \mathrm{H}),-0.04(\mathrm{~s}, 9 \mathrm{H}) ;{ }^{13} \mathrm{C} \mathrm{NMR}\left(\mathrm{C}_{6} \mathrm{D}_{6}, 100 \mathrm{MHz}\right) \delta 161.1,157.7$, 144.3, 133.2, 131.1, 118.2, 115.5, 98.9, 98.2, 87.8, 85.5, 79.7, 75.3, 72.4, 71.7, 64.5, 59.3, 56.3, $50.6,47.2,42.9,41.2,38.0,36.5,33.5,32.2,26.3,24.7,20.5,20.3,19.8,18.3,9.3,0.0$; IR (neat) $v_{\max } 2930,2329,1693,1449,1248,1170,839 \mathrm{~cm}^{-1} ;[\alpha]_{\mathrm{D}}^{25}=9.0(\mathrm{c} 0.2$, benzene); HRMS-ESI $(\mathrm{m} / \mathrm{z})$ calculated for $\left[\mathrm{M}+\mathrm{Na}^{+}\right]: 690.3797$, found: 690.3793 . 


\section{Reference:}

1. Paterson, I.; Steadman neé Doughty, V. A.; Malcolm D. McLeod, M. D.; Trieselmann, T, Tetrahedron, 2011, 67, 10119-10128

2. Yang, F.; Jeffery J. Newsome, J. J.; Curran, D. P. J. Am. Chem. Soc., 2006, 128, 1420014205

3. Forsyth, C. J.; Xu, J. Y.; Nguyen, S.; Samdal, I. A.; Briggs, L. R.; Rundberget,T;

Sandvik, M.; Miles, C. O. J. Am. Chem. Soc. 2006, 128, 15114 


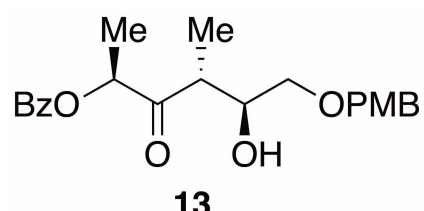

13

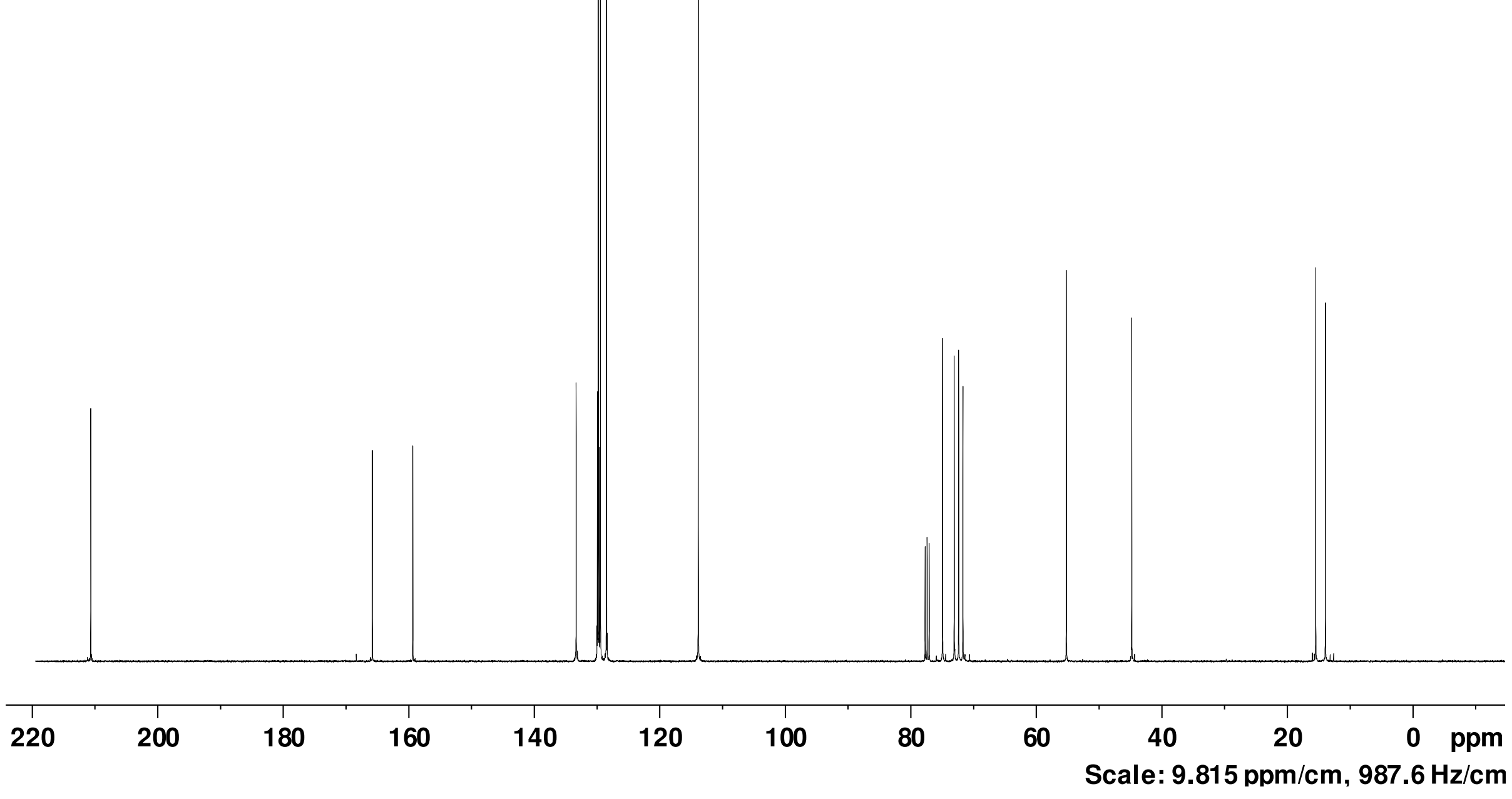


으유

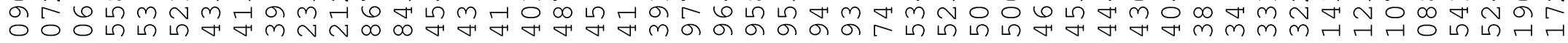

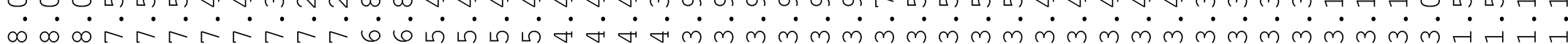

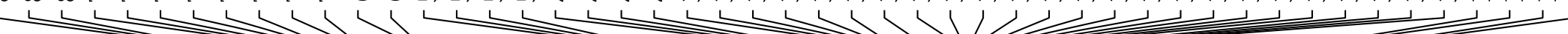
IIIII

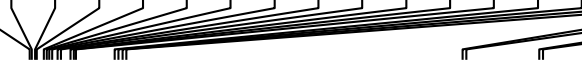

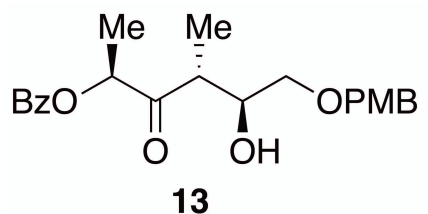

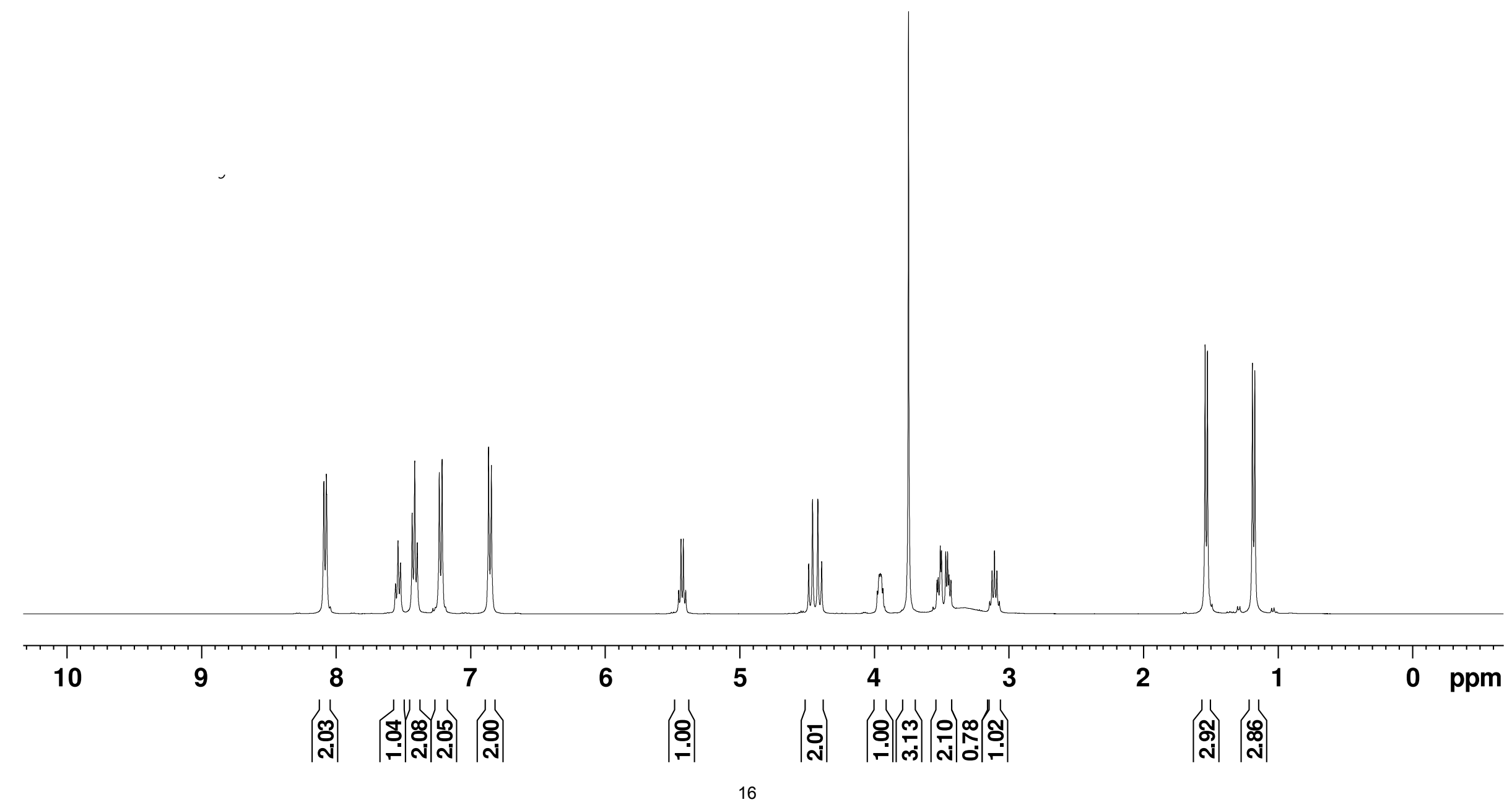




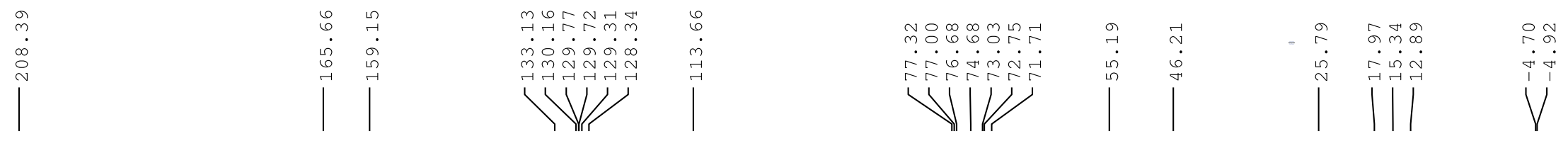

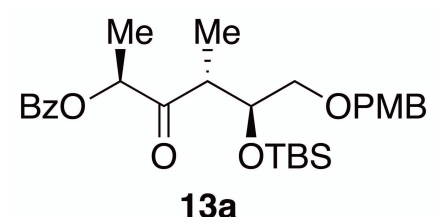

$13 a$

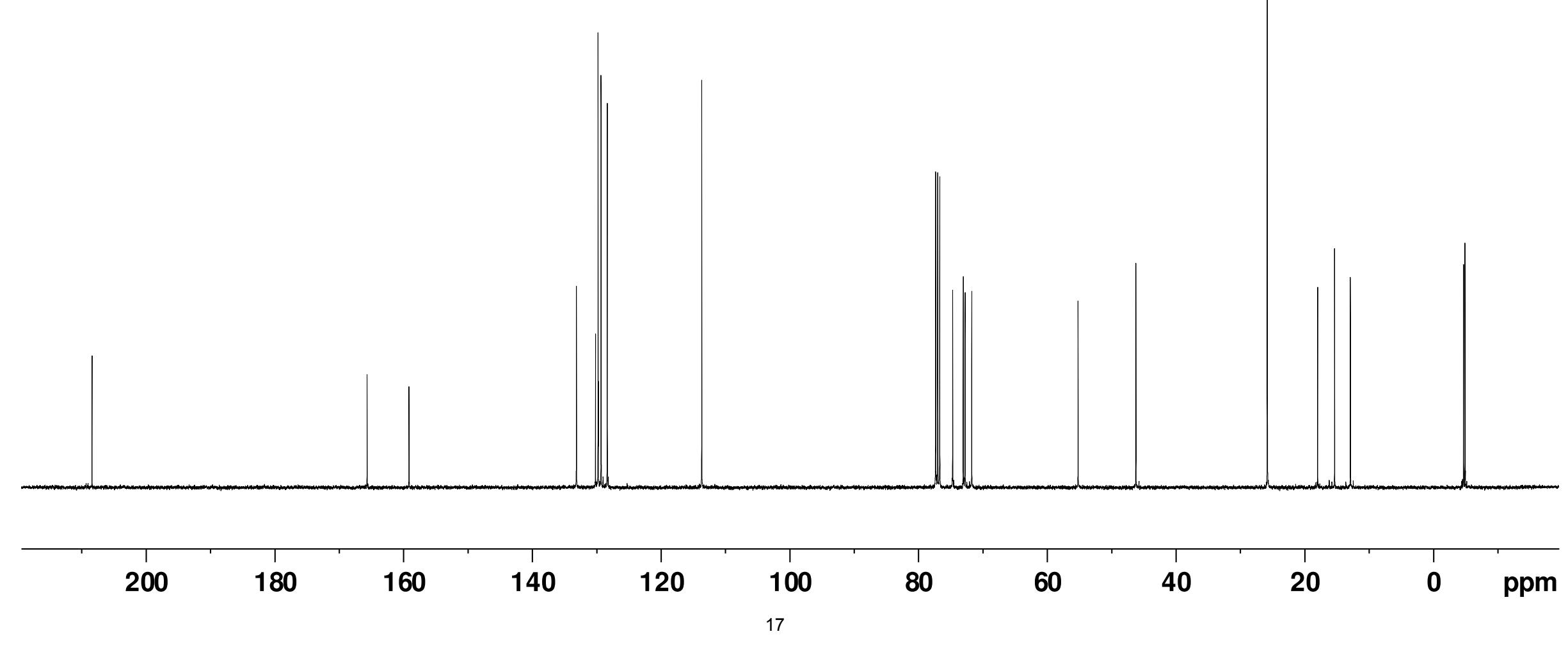




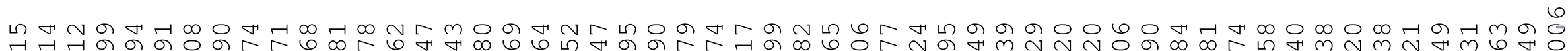

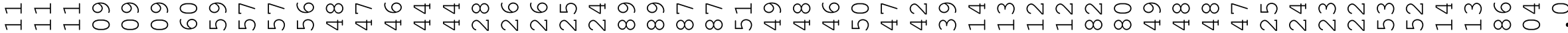

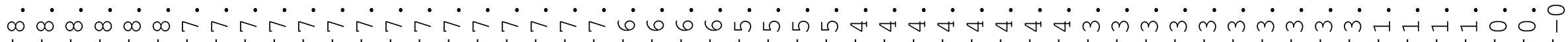

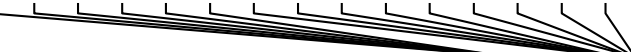

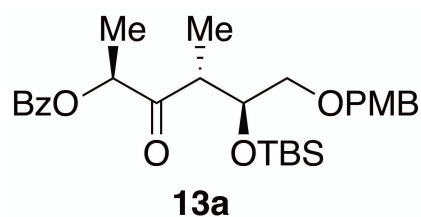
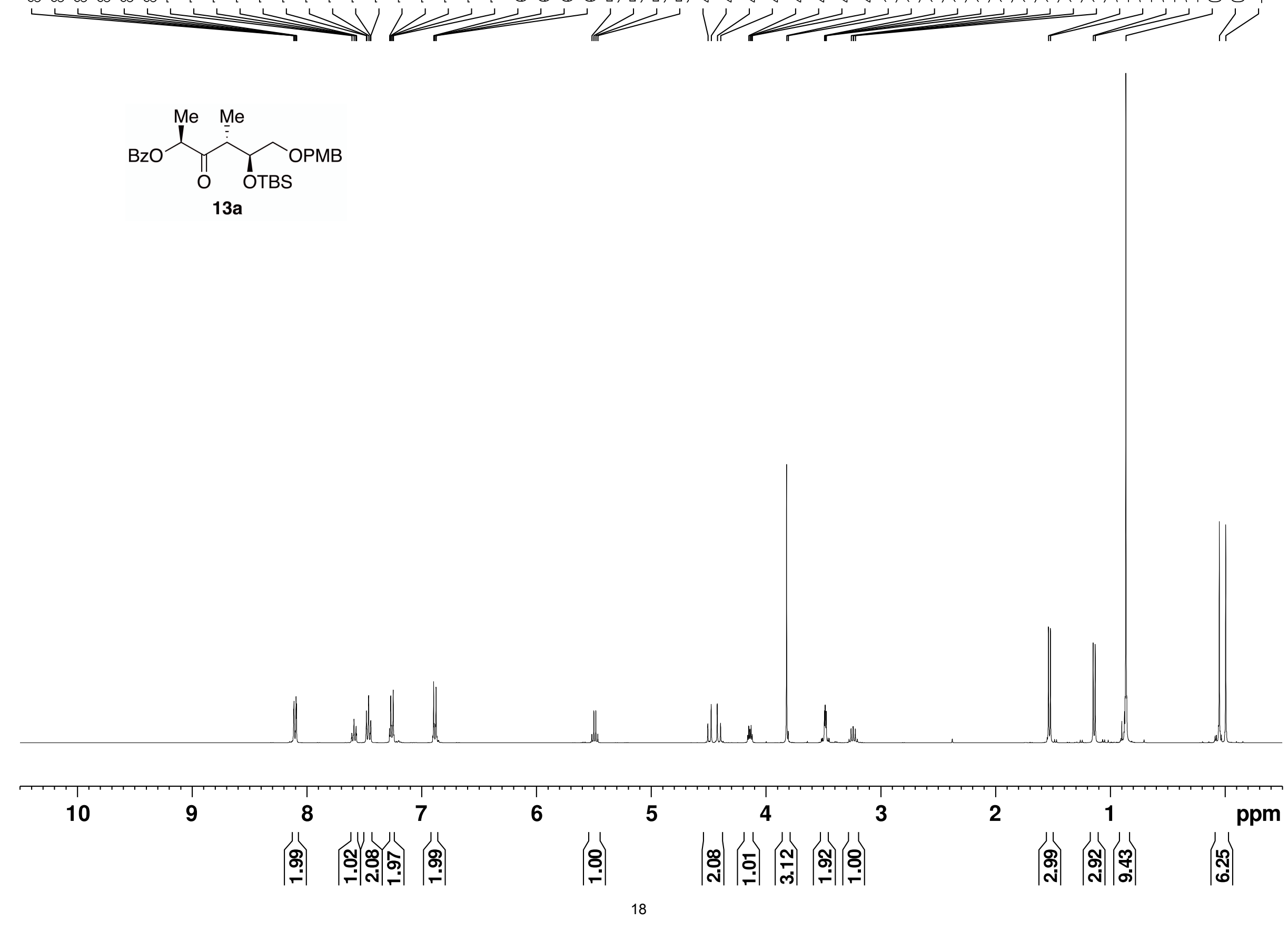


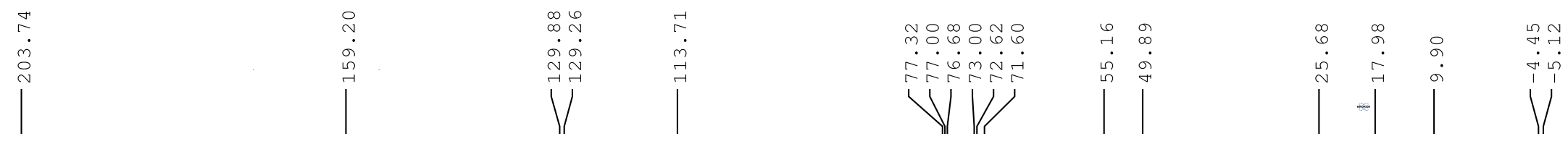
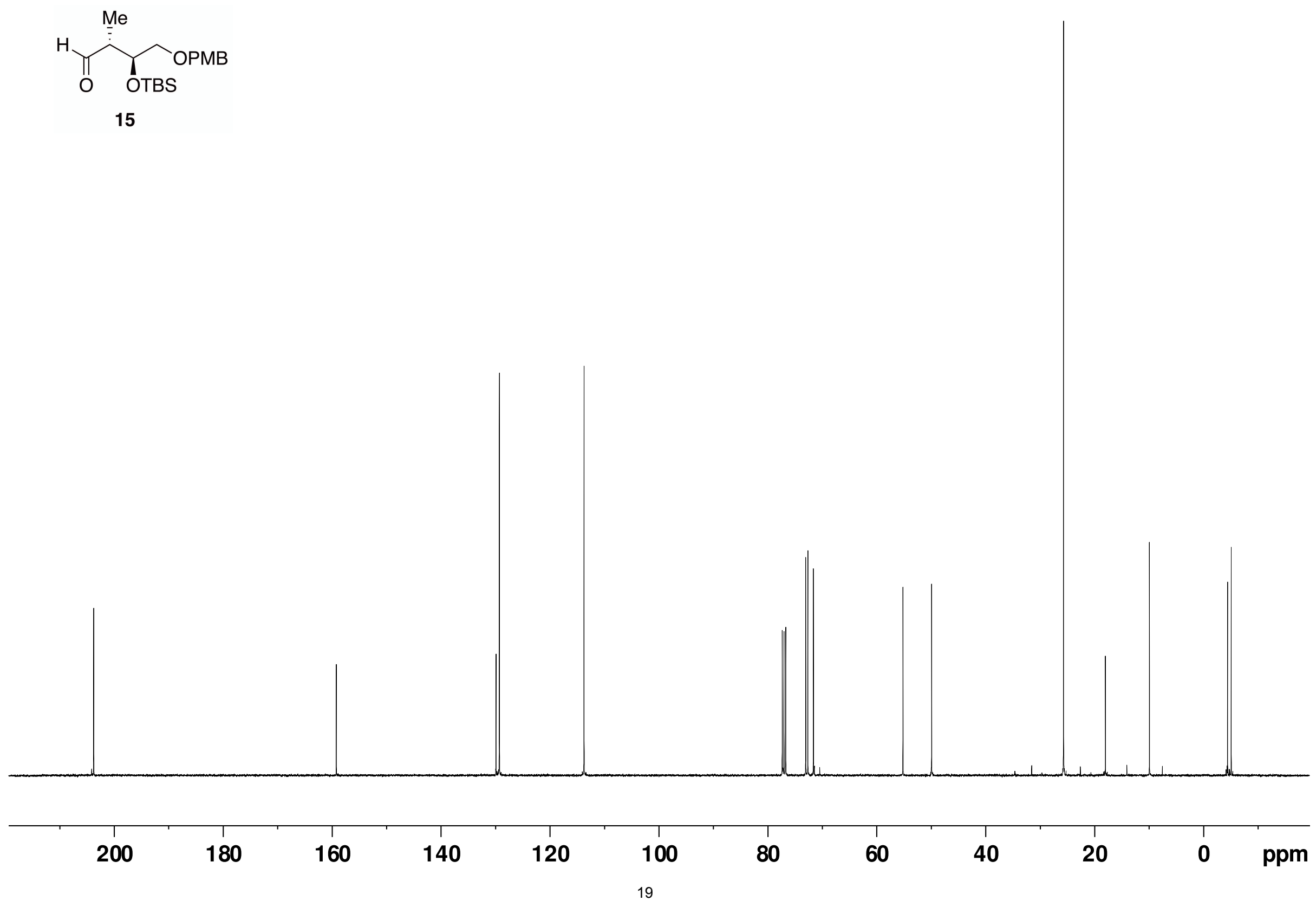

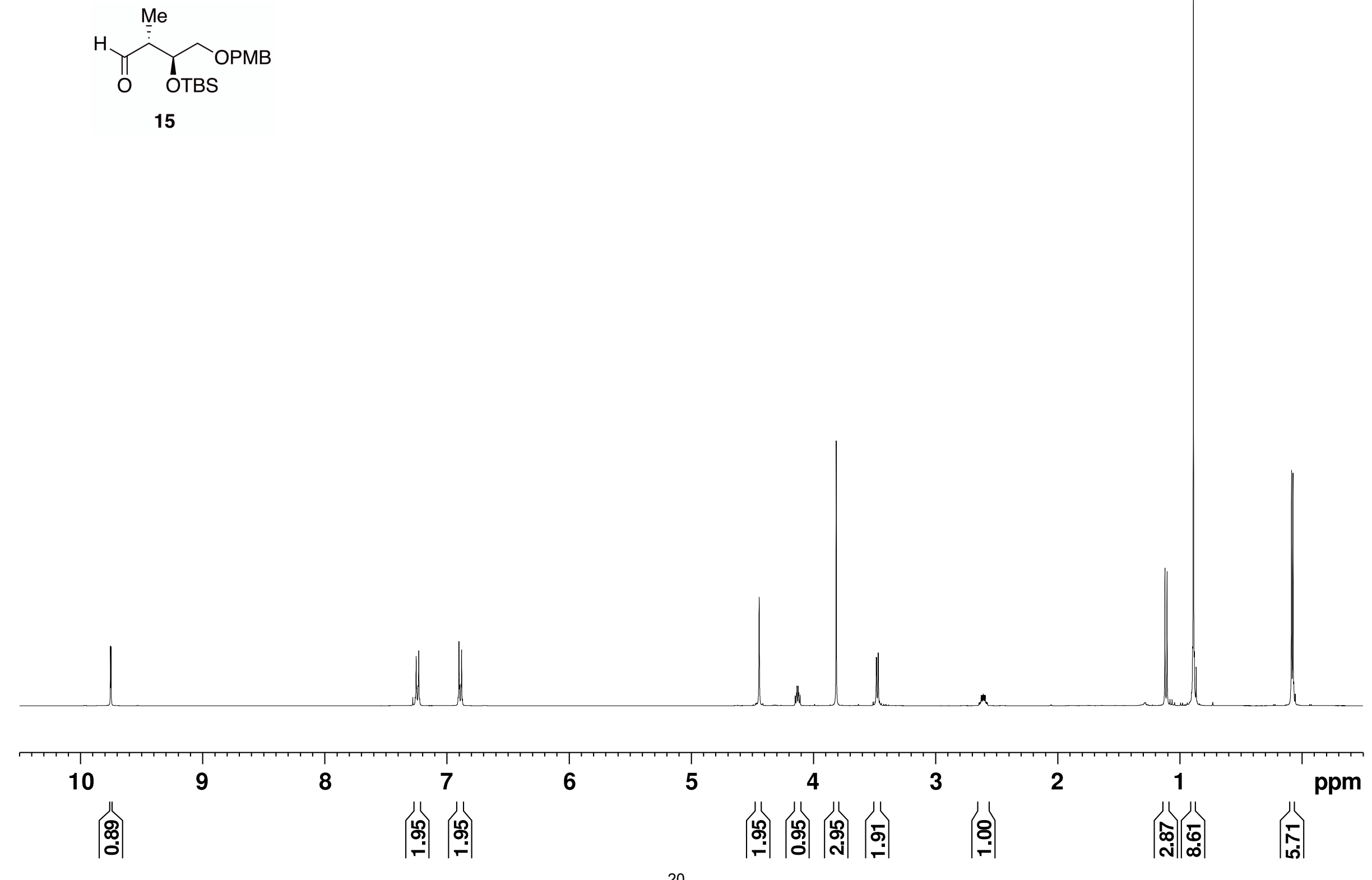


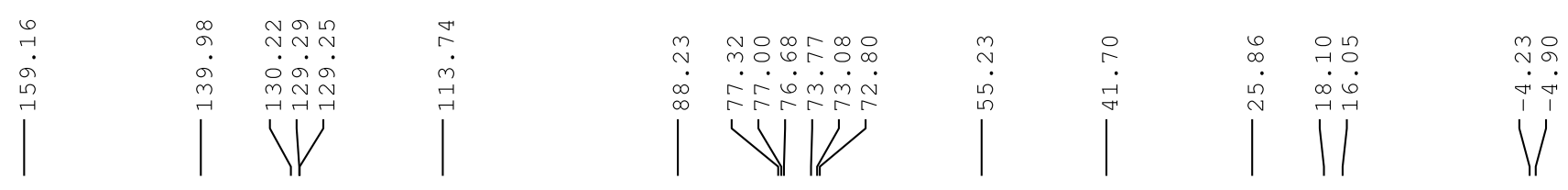
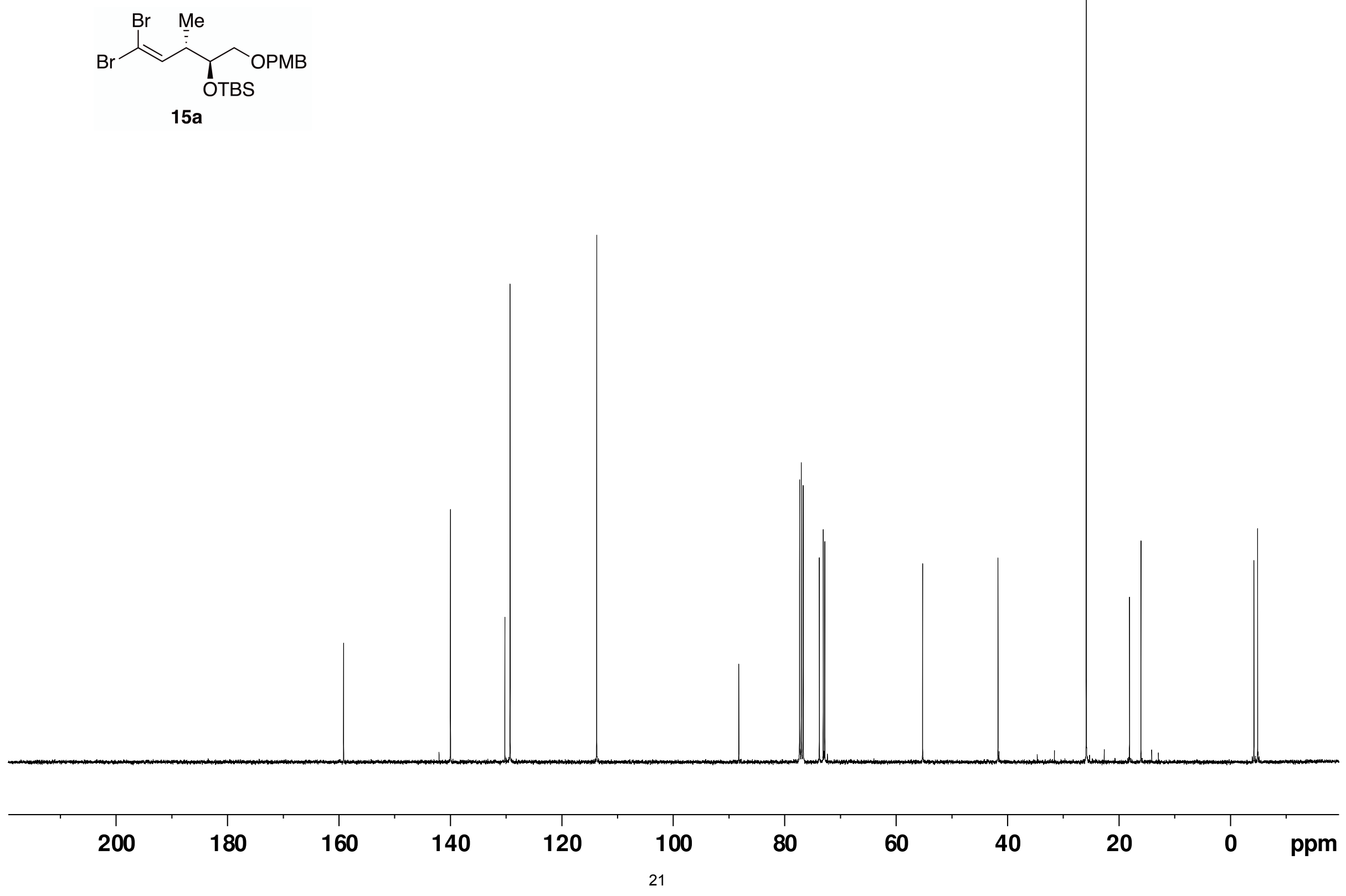
음유 N N

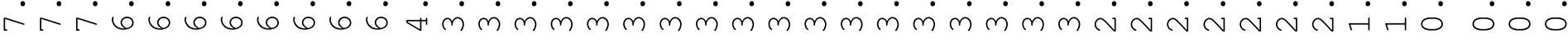

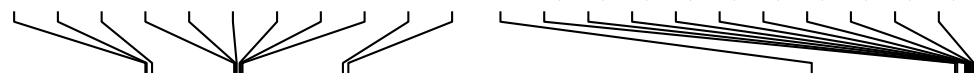

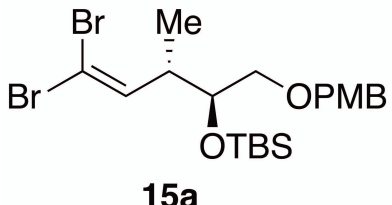

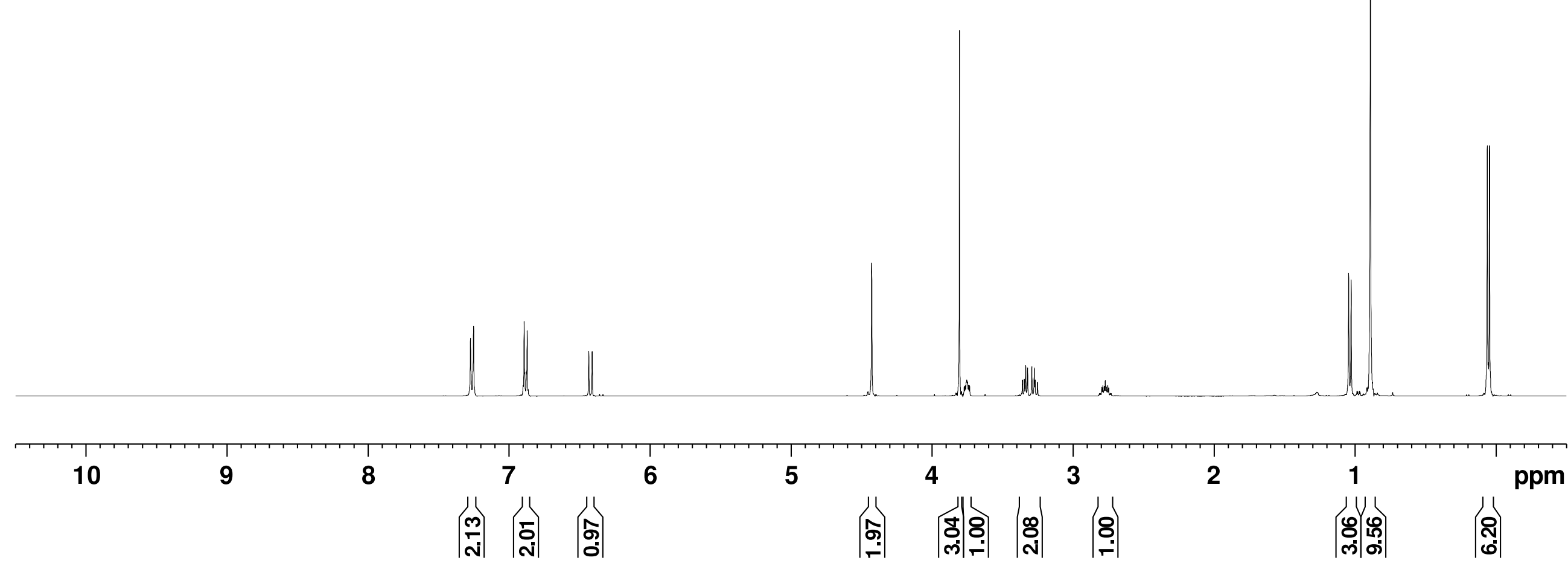




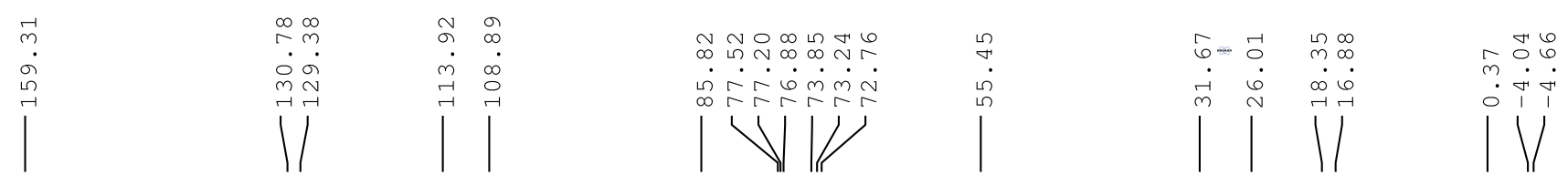
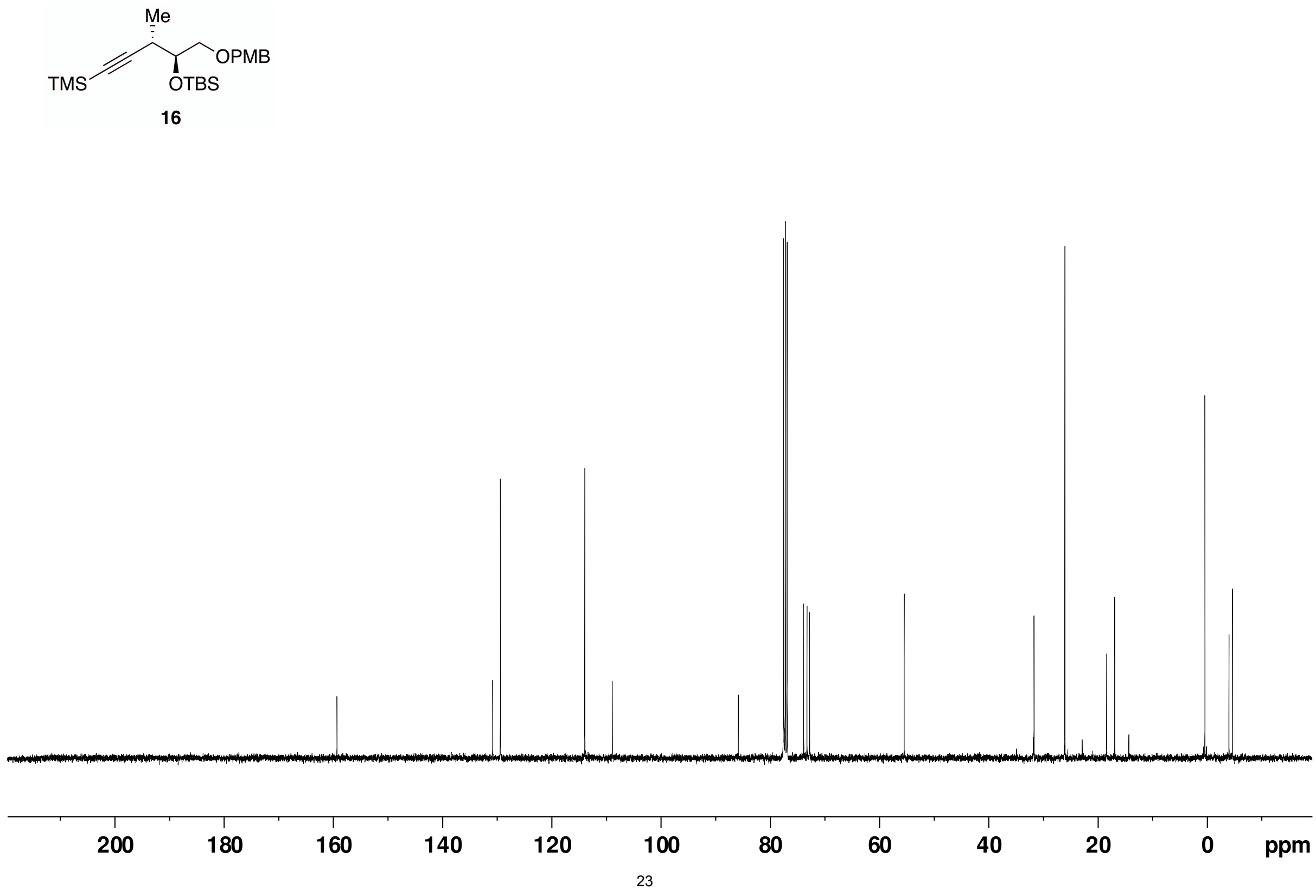
ก요

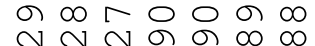
$\therefore \sim r \dot{0} \dot{0} \dot{0}$

4 ○ก

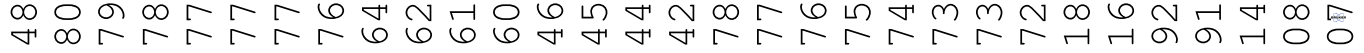
$\dot{\sigma} \dot{m} \dot{m} \dot{m} \dot{m} \dot{m} \dot{m} \dot{m} \dot{m} \dot{m} \dot{m} \dot{m} \dot{N} \dot{N} \dot{N} \dot{N} \dot{N} \dot{N} \dot{\sim} \dot{\sim} \dot{0} \dot{0} \dot{0}$
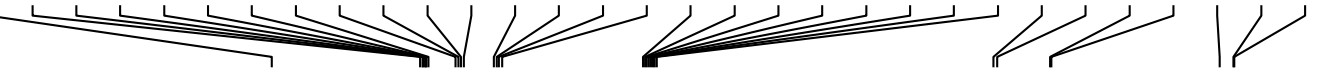
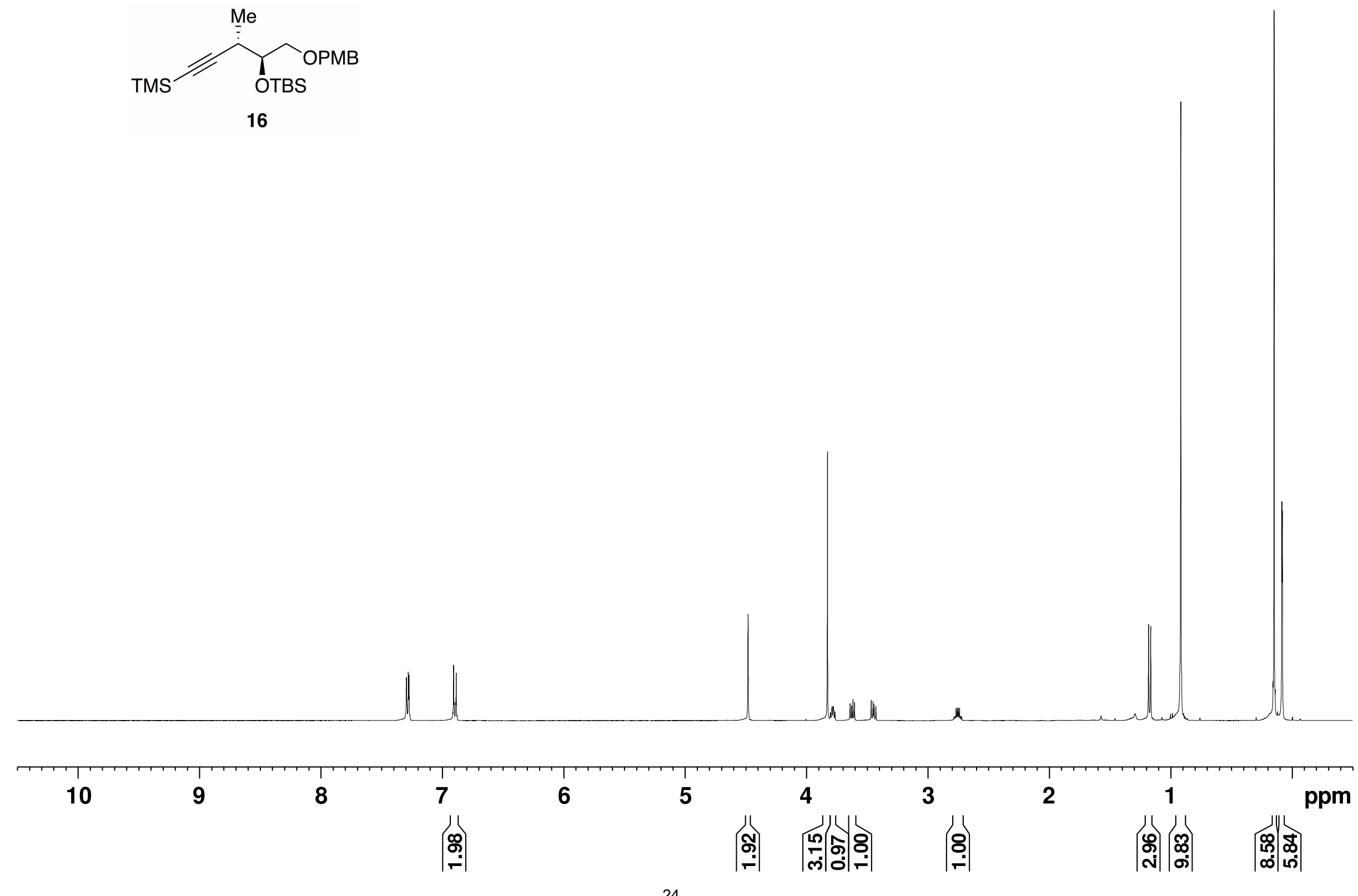


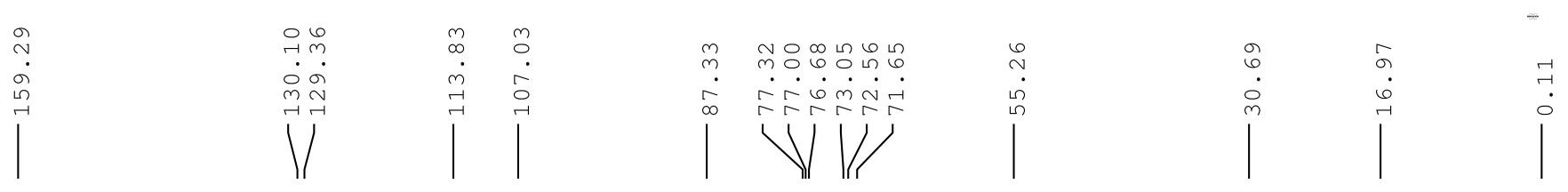
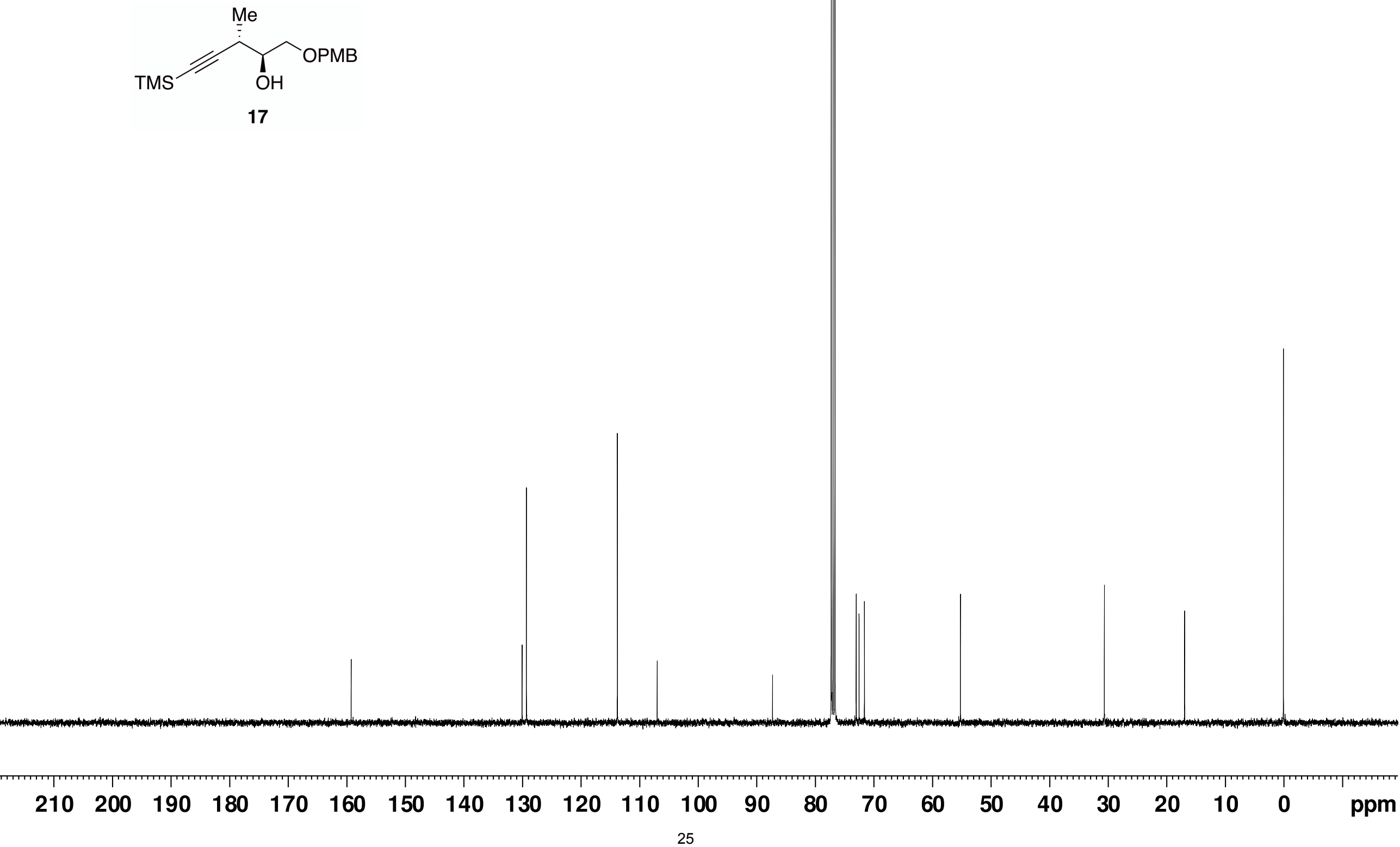


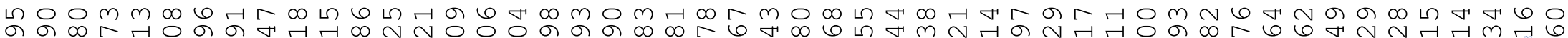

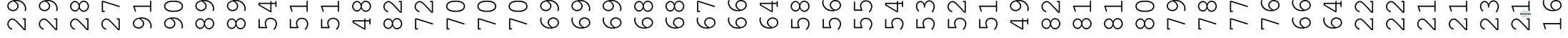

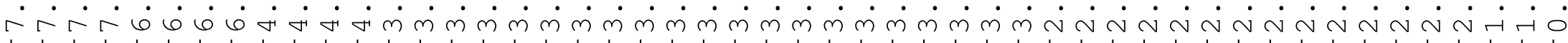<smiles>CC#CC(C)C(O)CO[Na]</smiles>
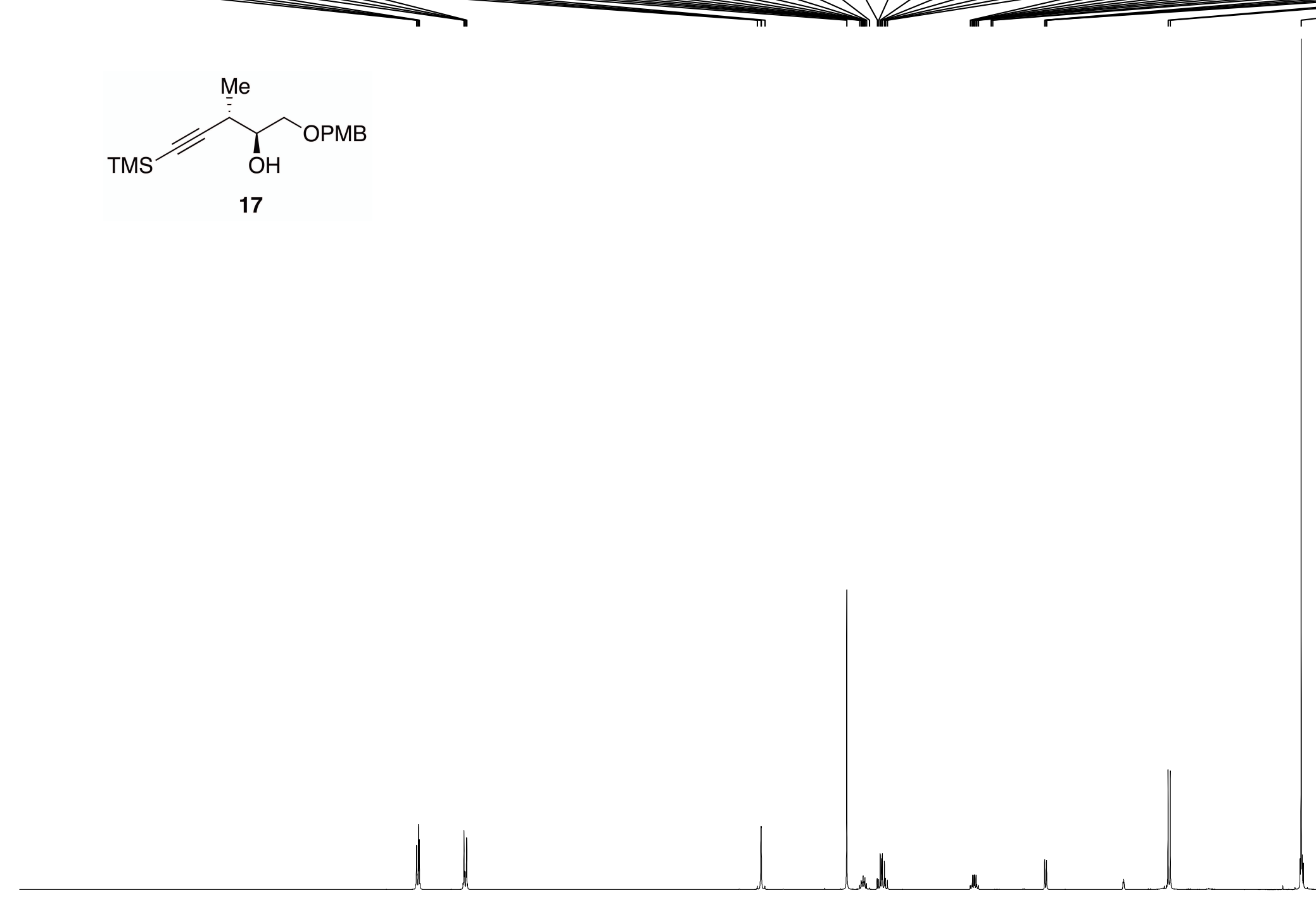

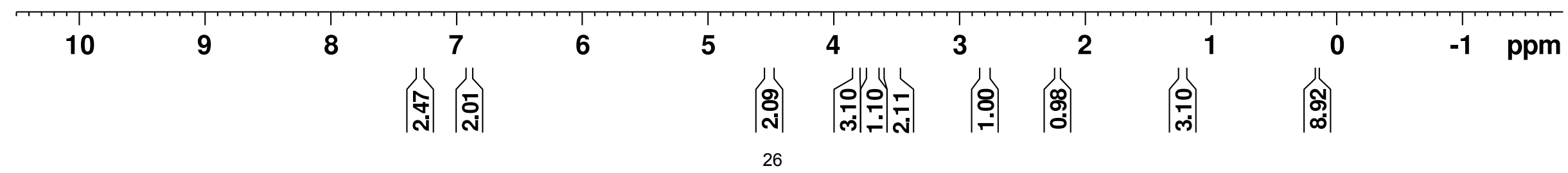




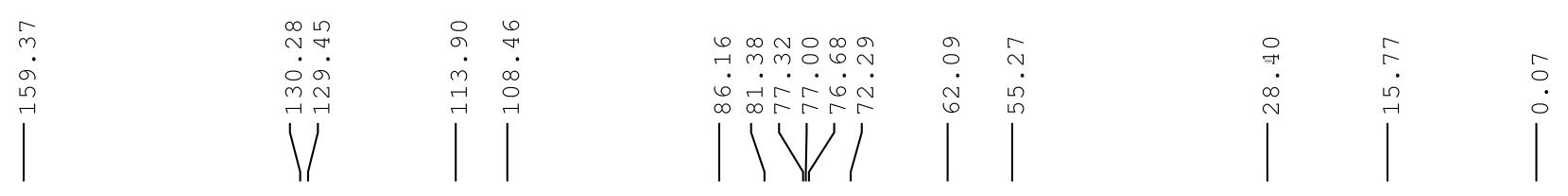

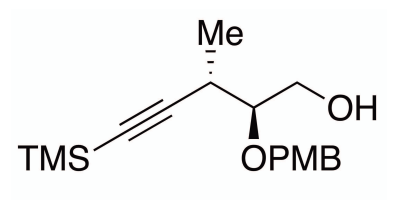

19

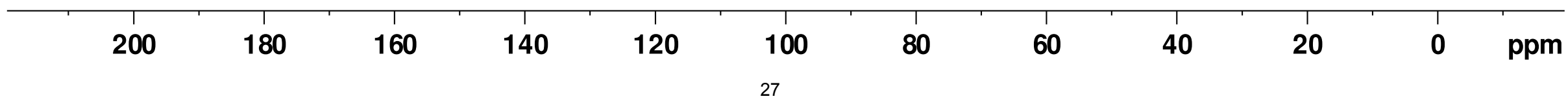




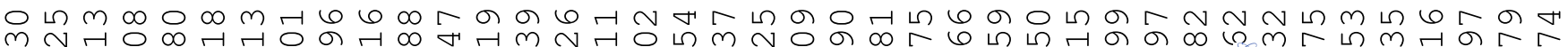
$m$ m

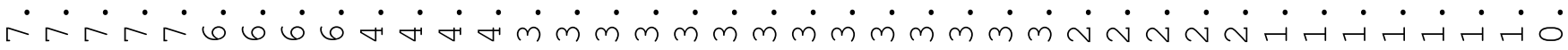

3

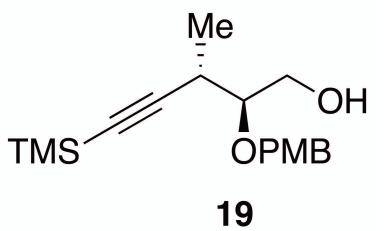

19

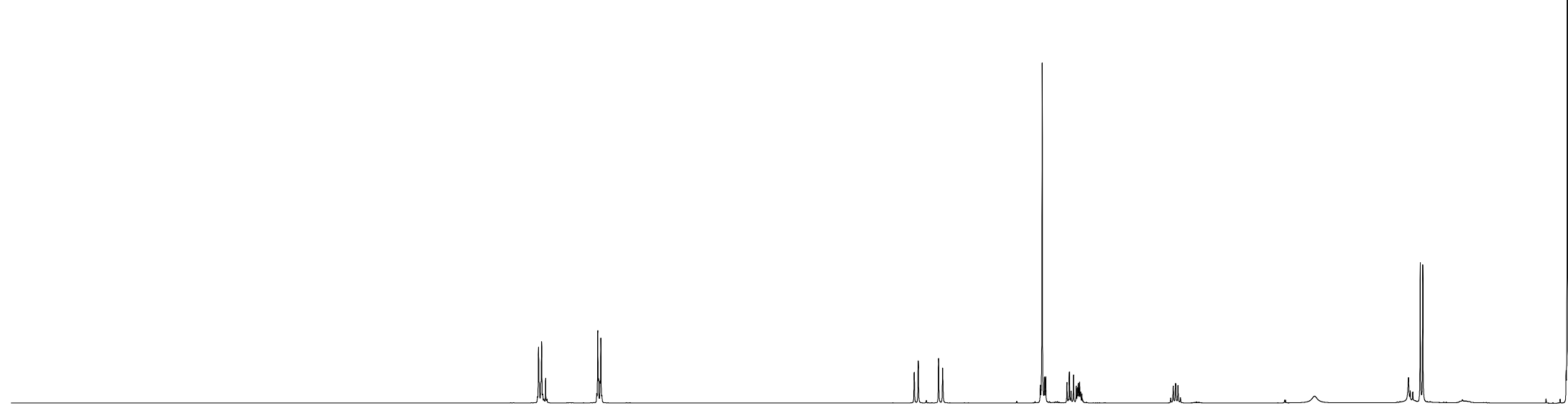

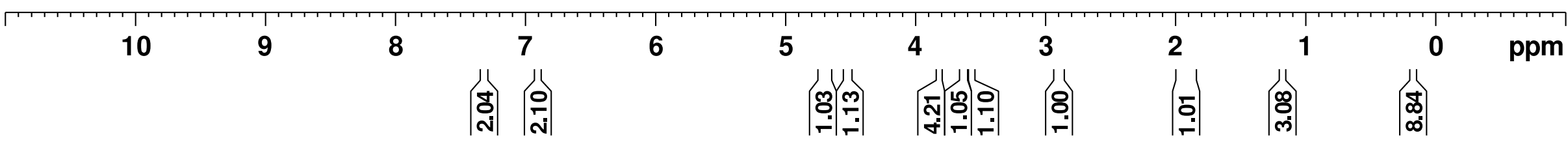




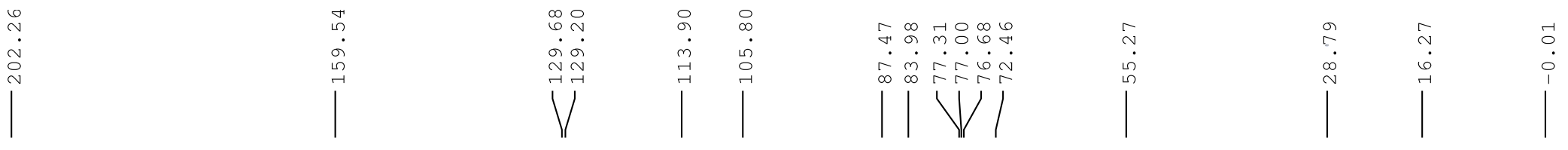

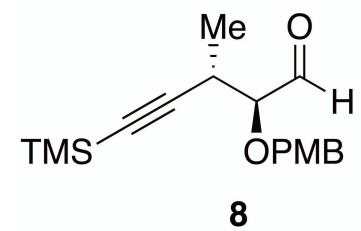

\begin{tabular}{lllll|ll|lllll}
\hline 200 & 180 & 160 & 140 & 120 & 100 & 80 & 60 & 40 & 20 & 0 & ppm
\end{tabular}



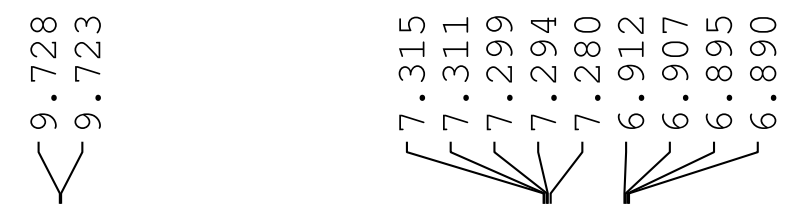

ஸே ㄴ $\dot{\forall} \dot{\sigma} \dot{\sigma} \dot{\sim} \dot{m} \dot{m} \dot{m} \dot{m} \dot{\sim} \dot{\sim} \dot{\sim} \dot{\sim} \dot{\sim} \dot{\sim}$ $\rightarrow 1$

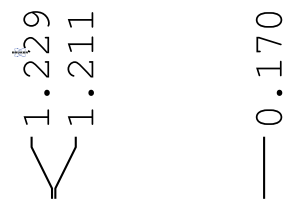
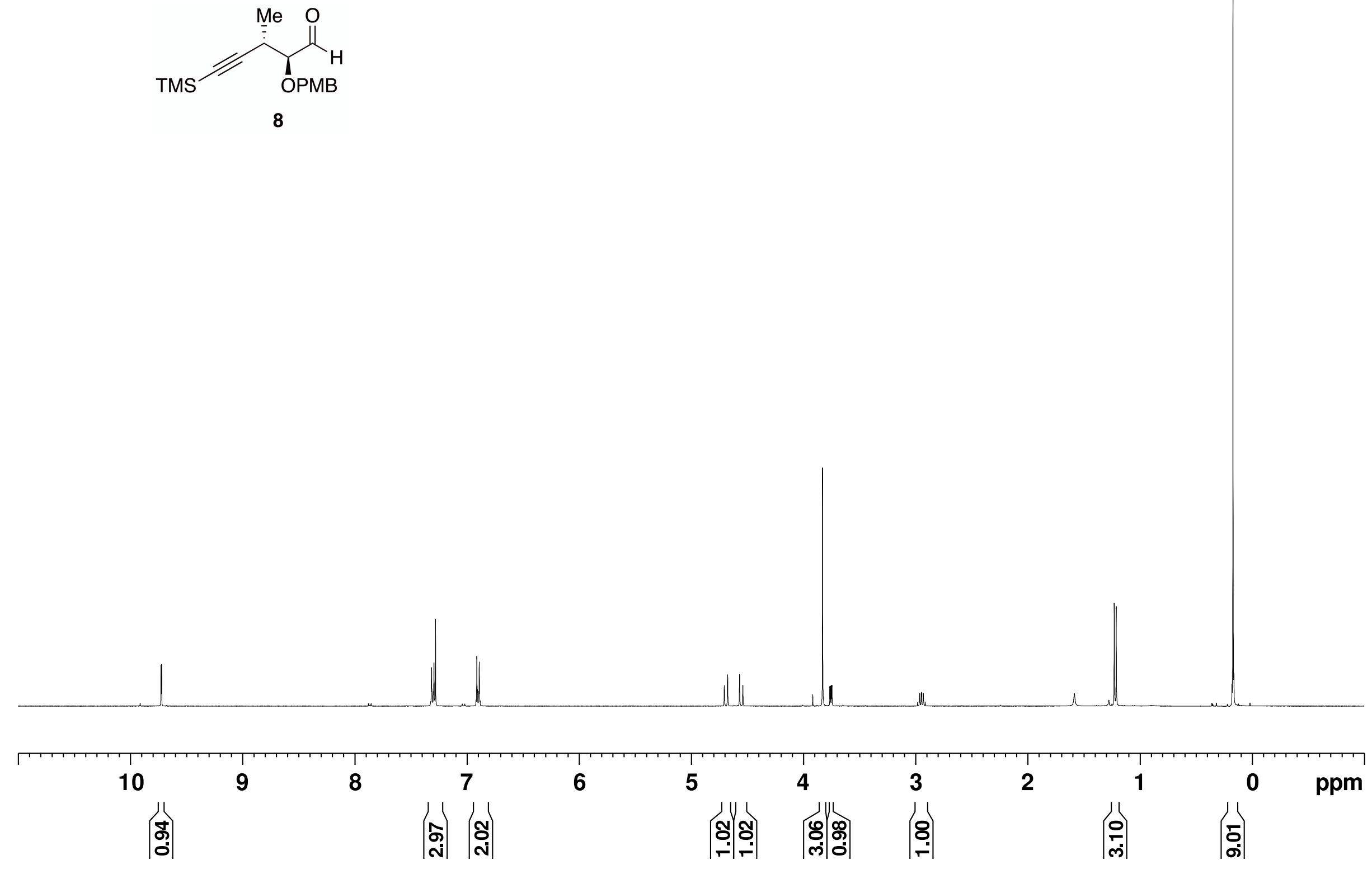


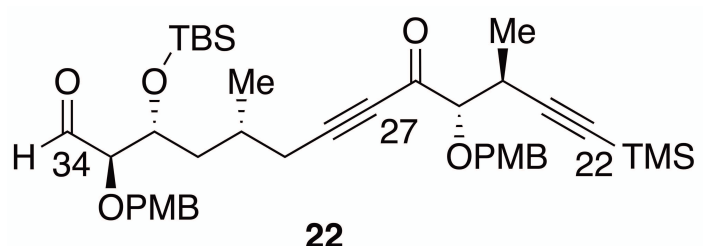

22

\begin{tabular}{llll|l|l|llllll}
\hline 200 & 180 & 160 & 140 & 120 & 100 & 80 & 60 & 40 & 20 & 0 & ppm
\end{tabular}




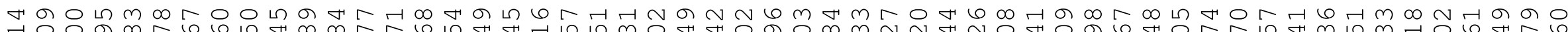

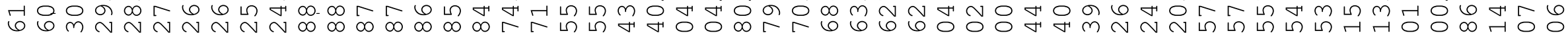

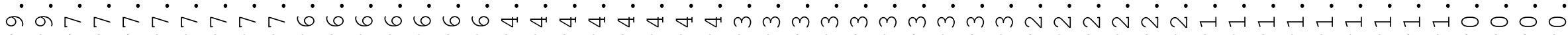

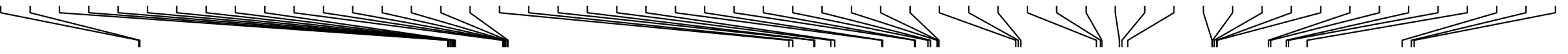

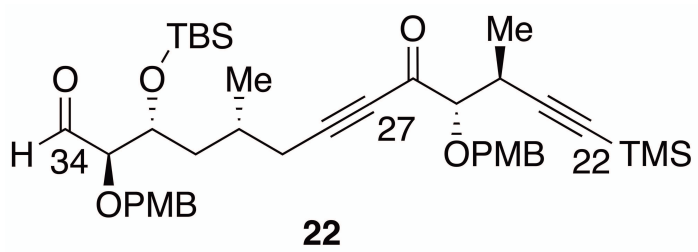



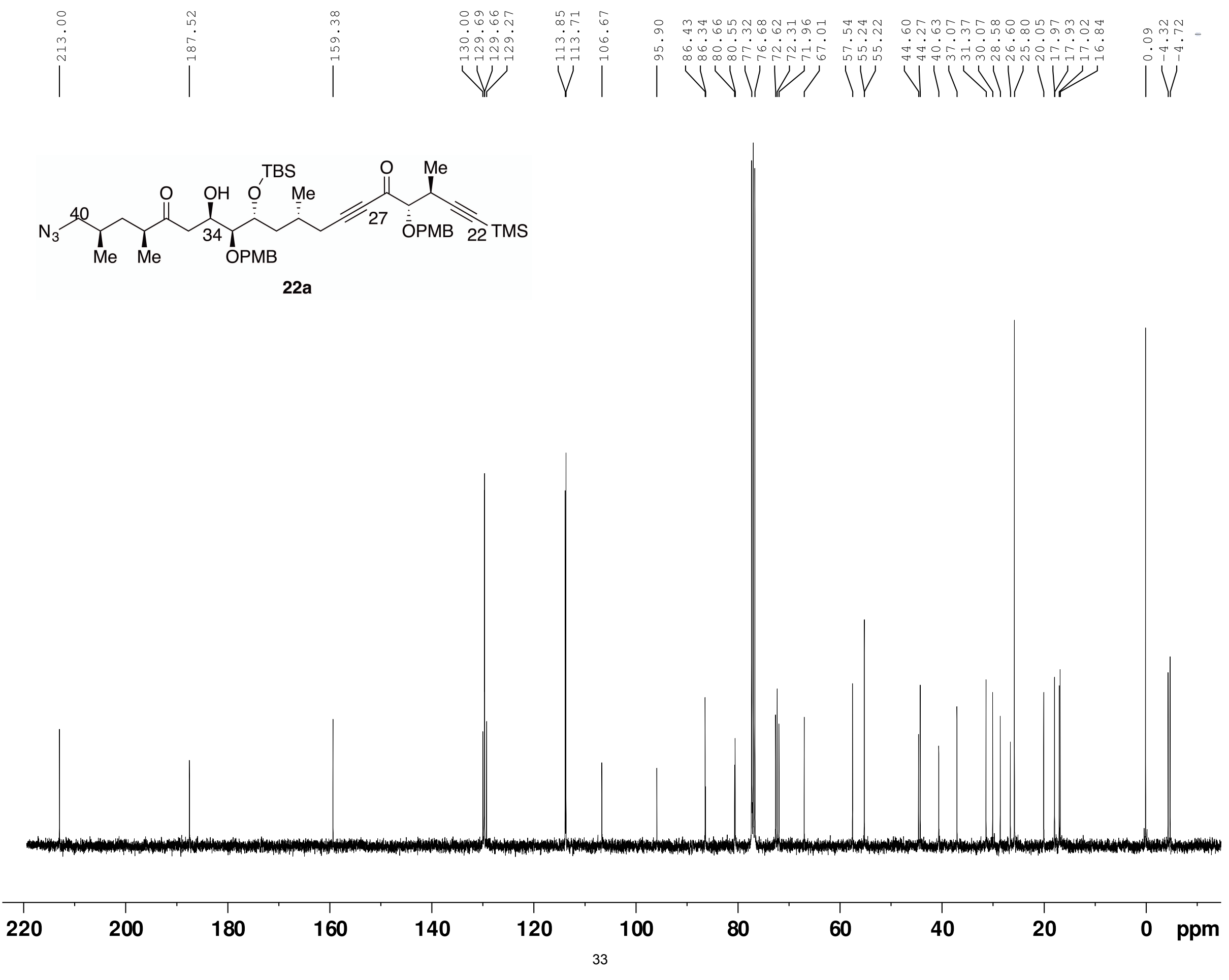

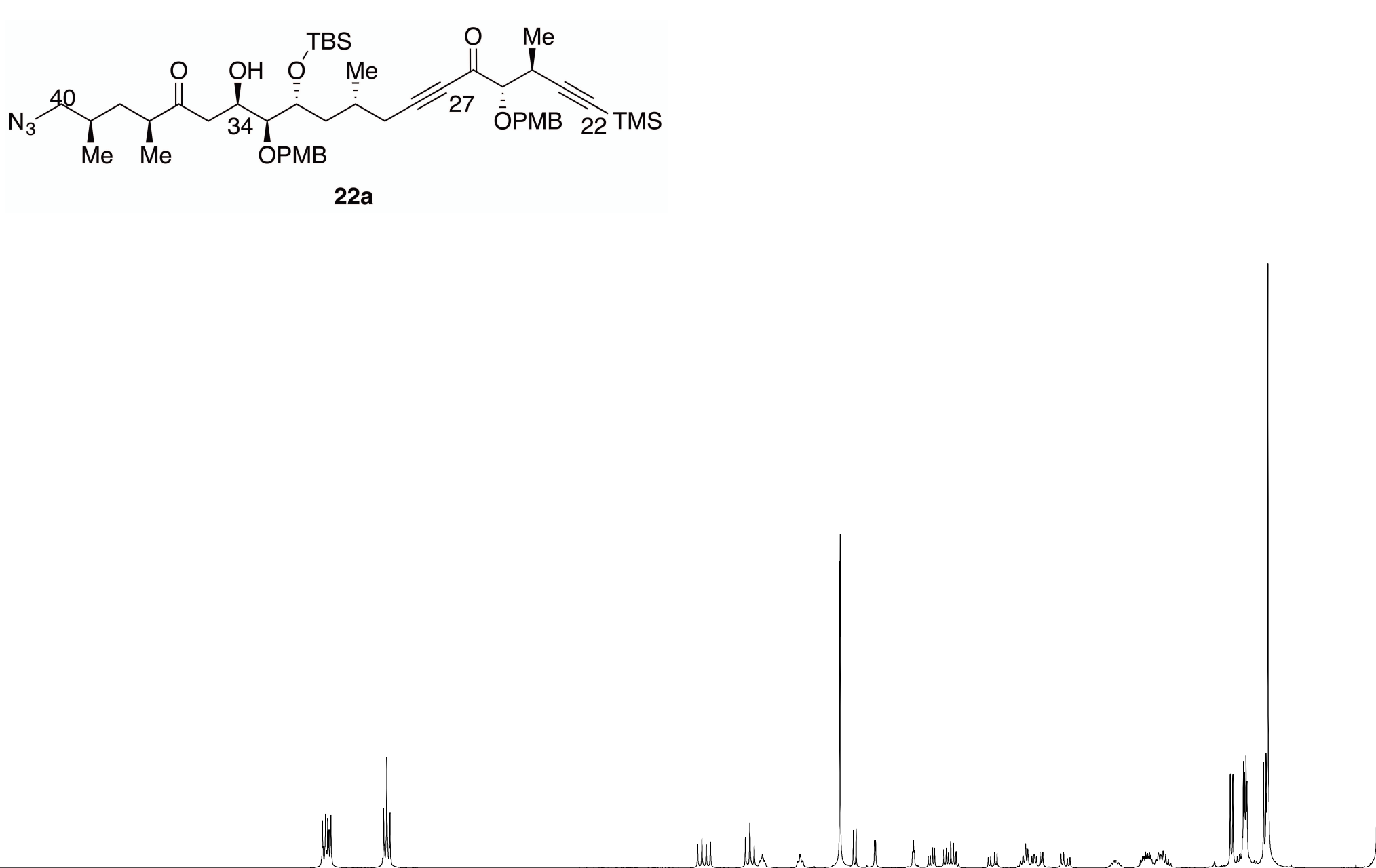

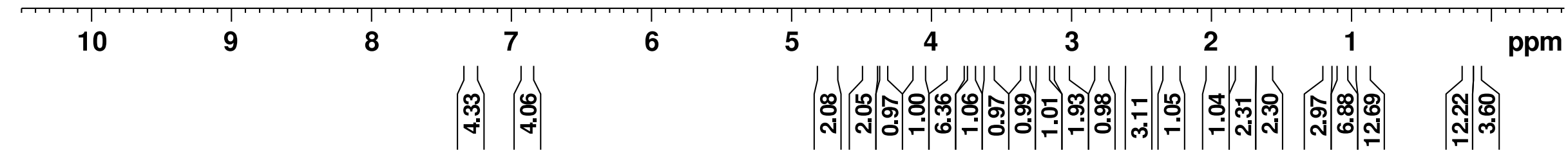




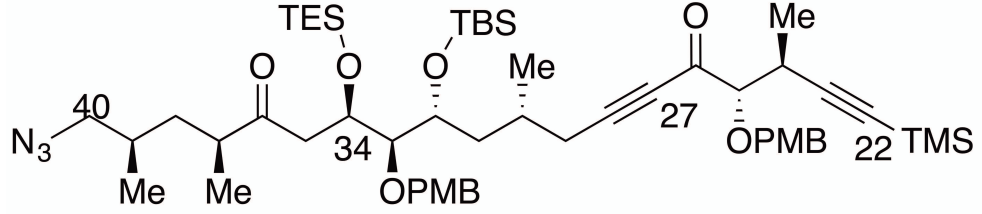

23

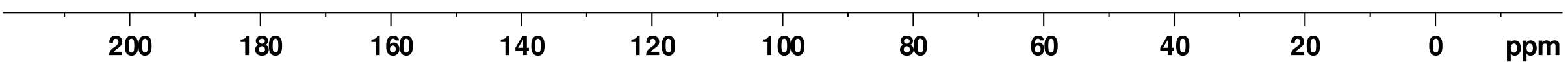




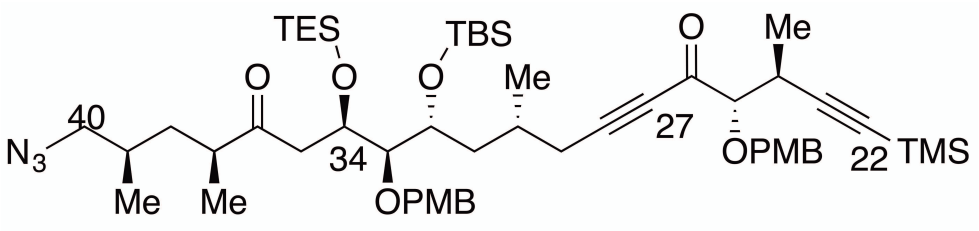

23

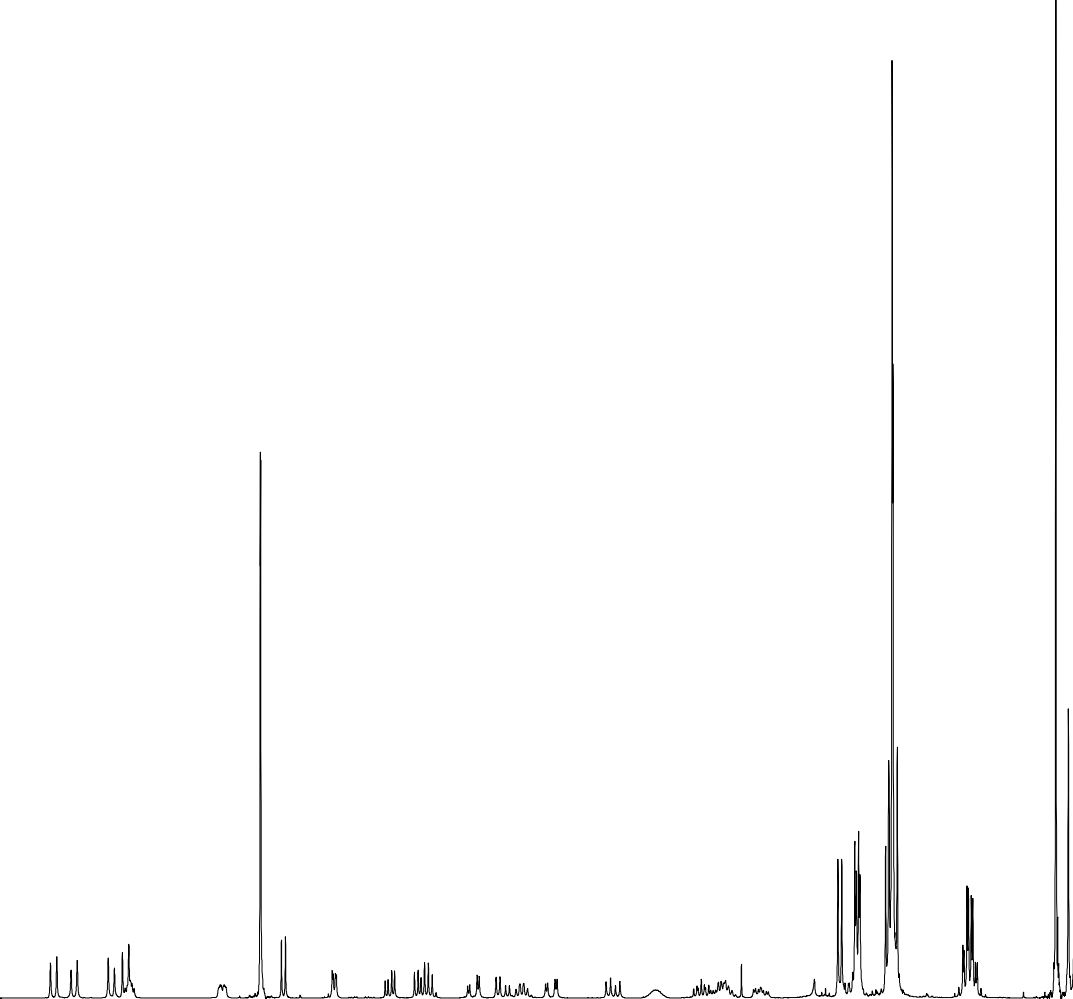

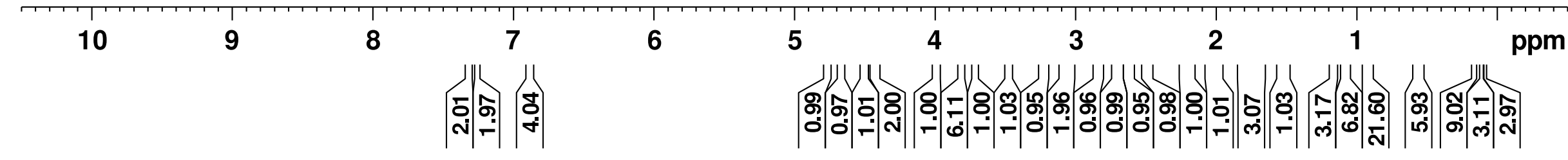



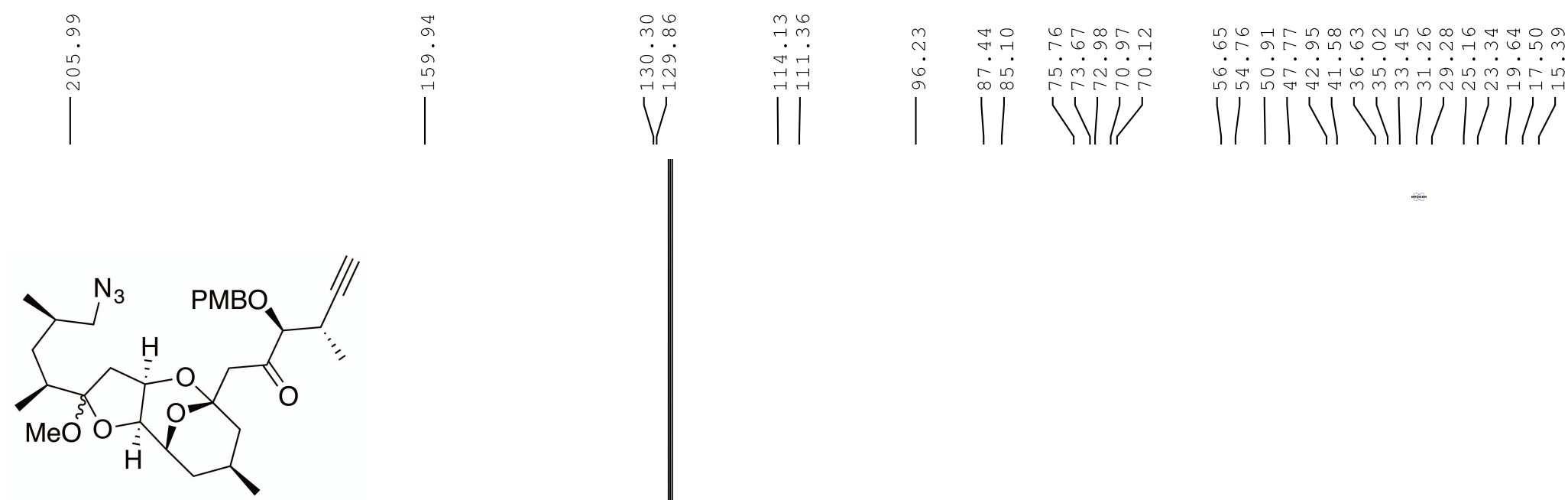

25

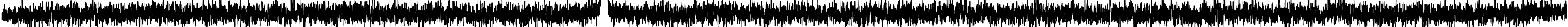

\begin{tabular}{rrrrrrrrrrrrrr}
\hline 200 & 180 & 160 & 140 & 120 & 100 & 80 & 60 & 40 & 20 & 0 & ppm
\end{tabular}



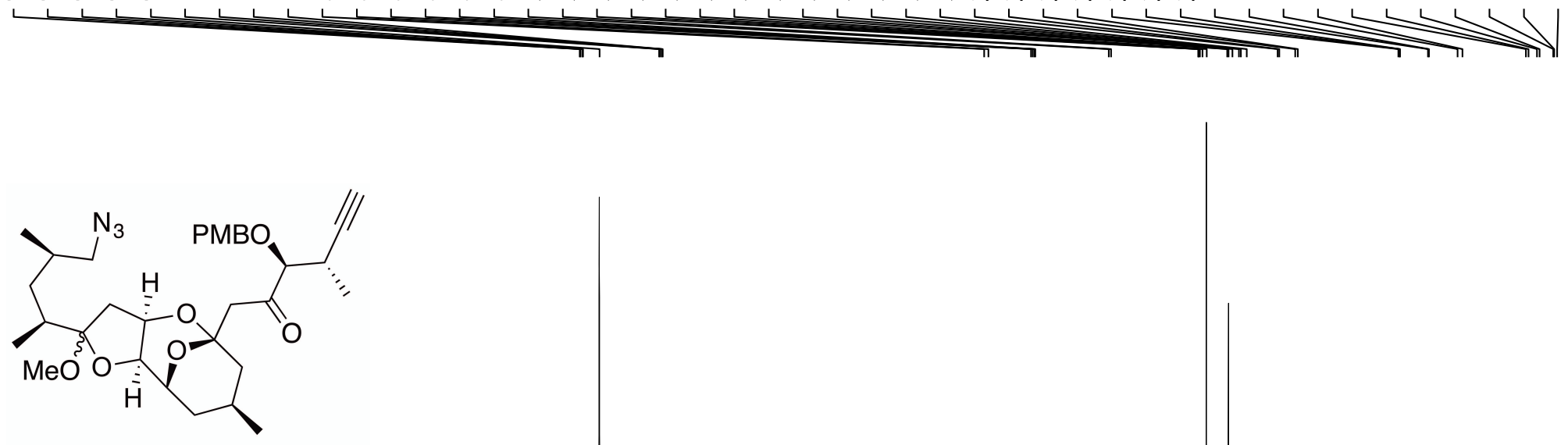

25

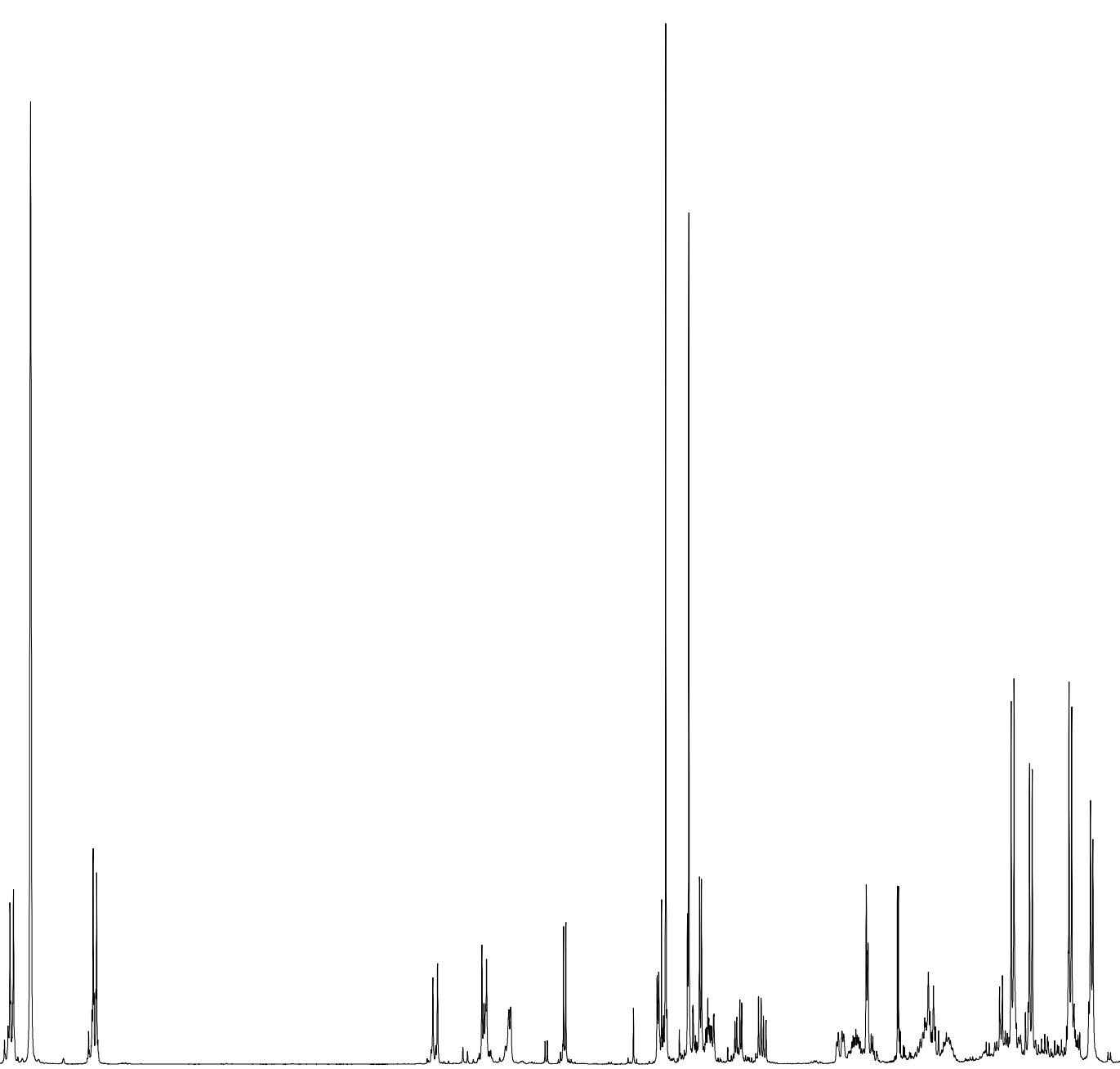

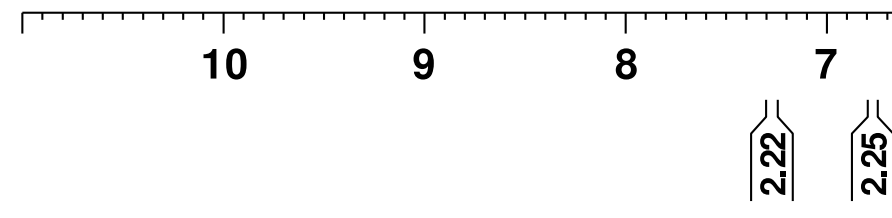

6

Nָก
5

\section{4}

1) للा

2

1

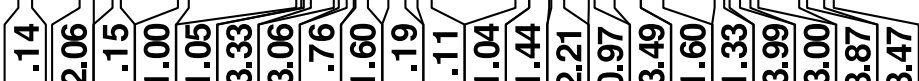



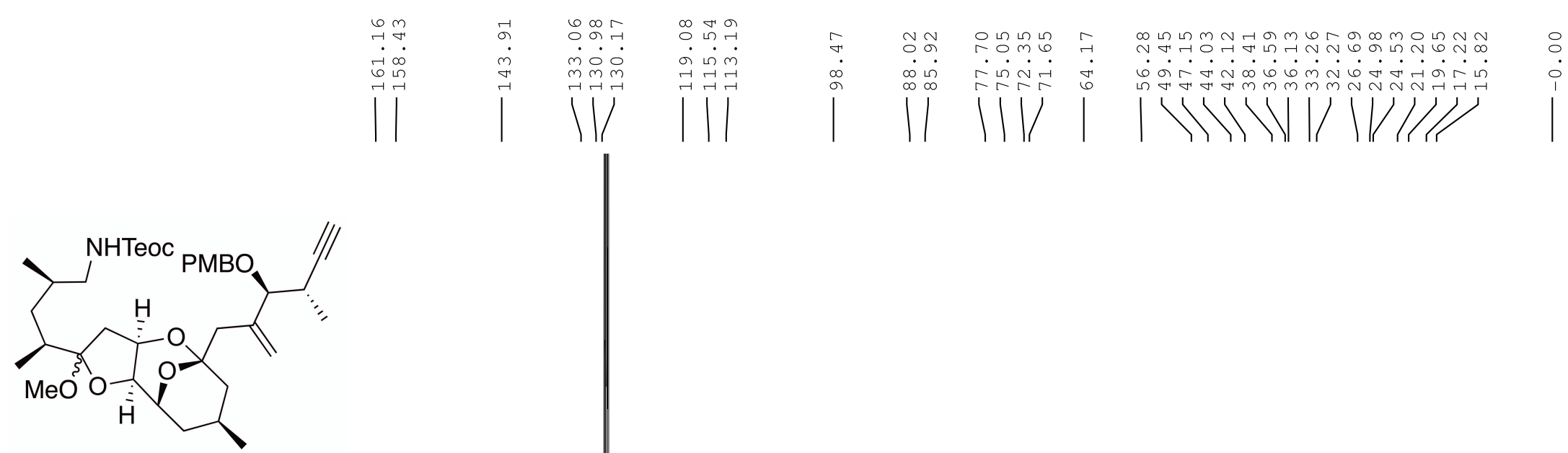

26

1 Ww

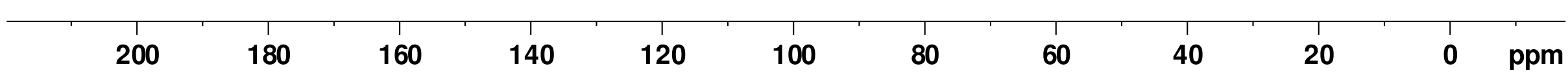




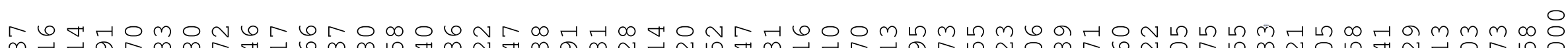

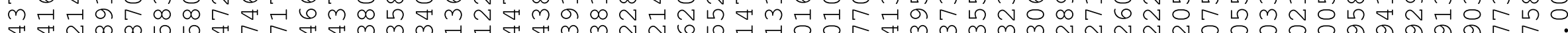

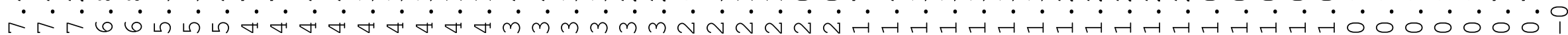
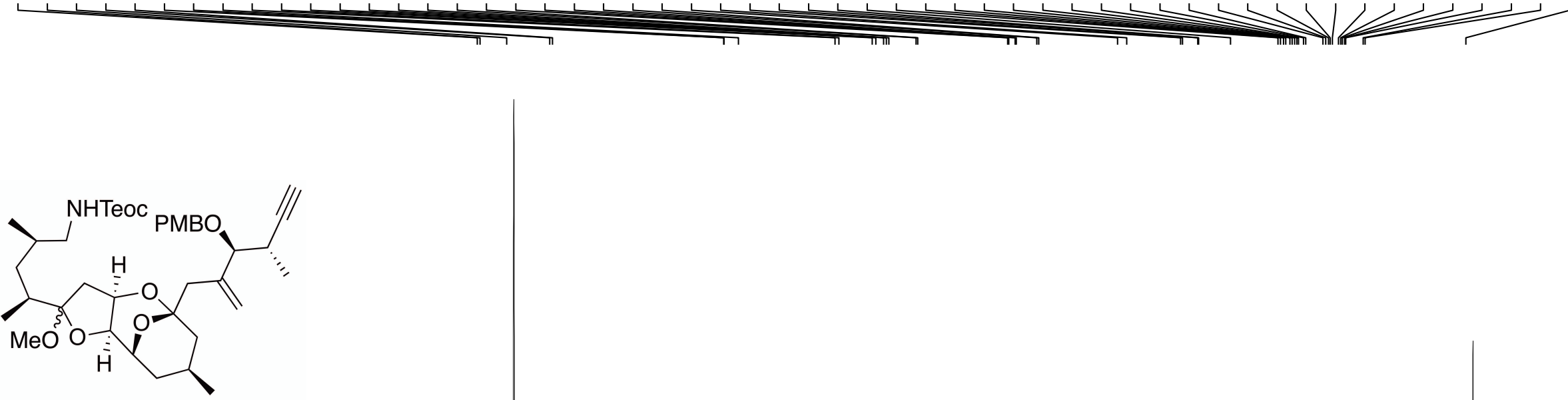

26
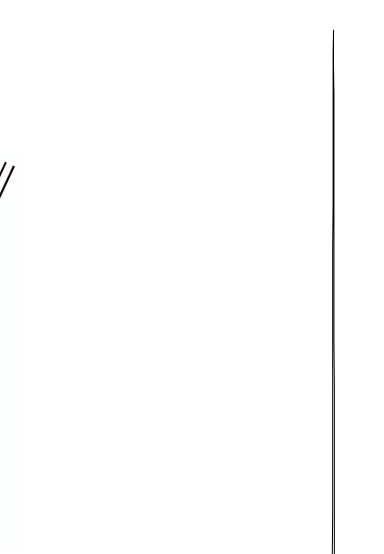

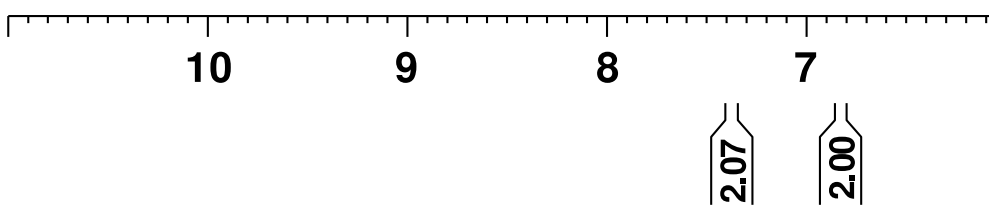

5

4

3

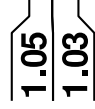

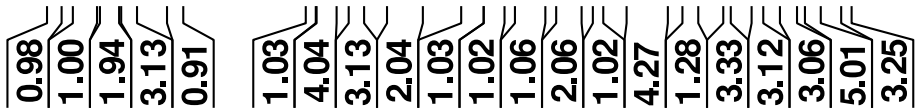

o ppm 


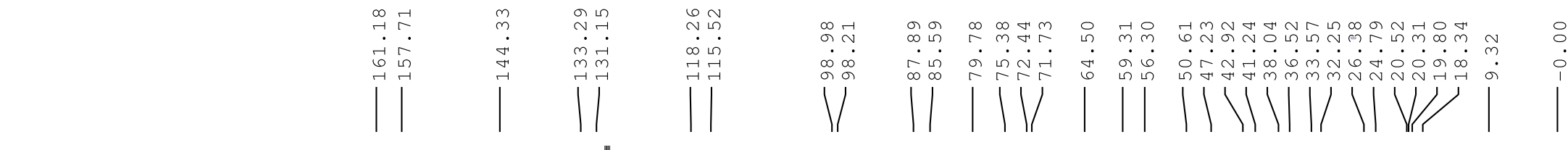

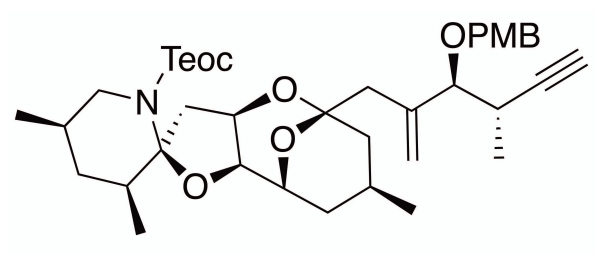

6

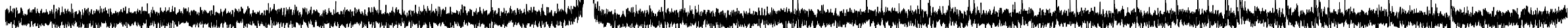

\begin{tabular}{rrrrrrrrrrrrrr}
\hline 200 & 180 & 160 & 140 & 120 & 100 & 80 & 60 & 40 & 20 & 0 & ppm
\end{tabular}




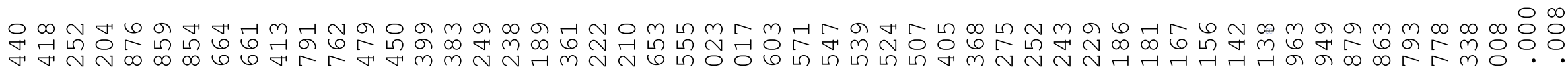

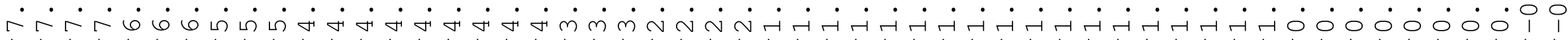
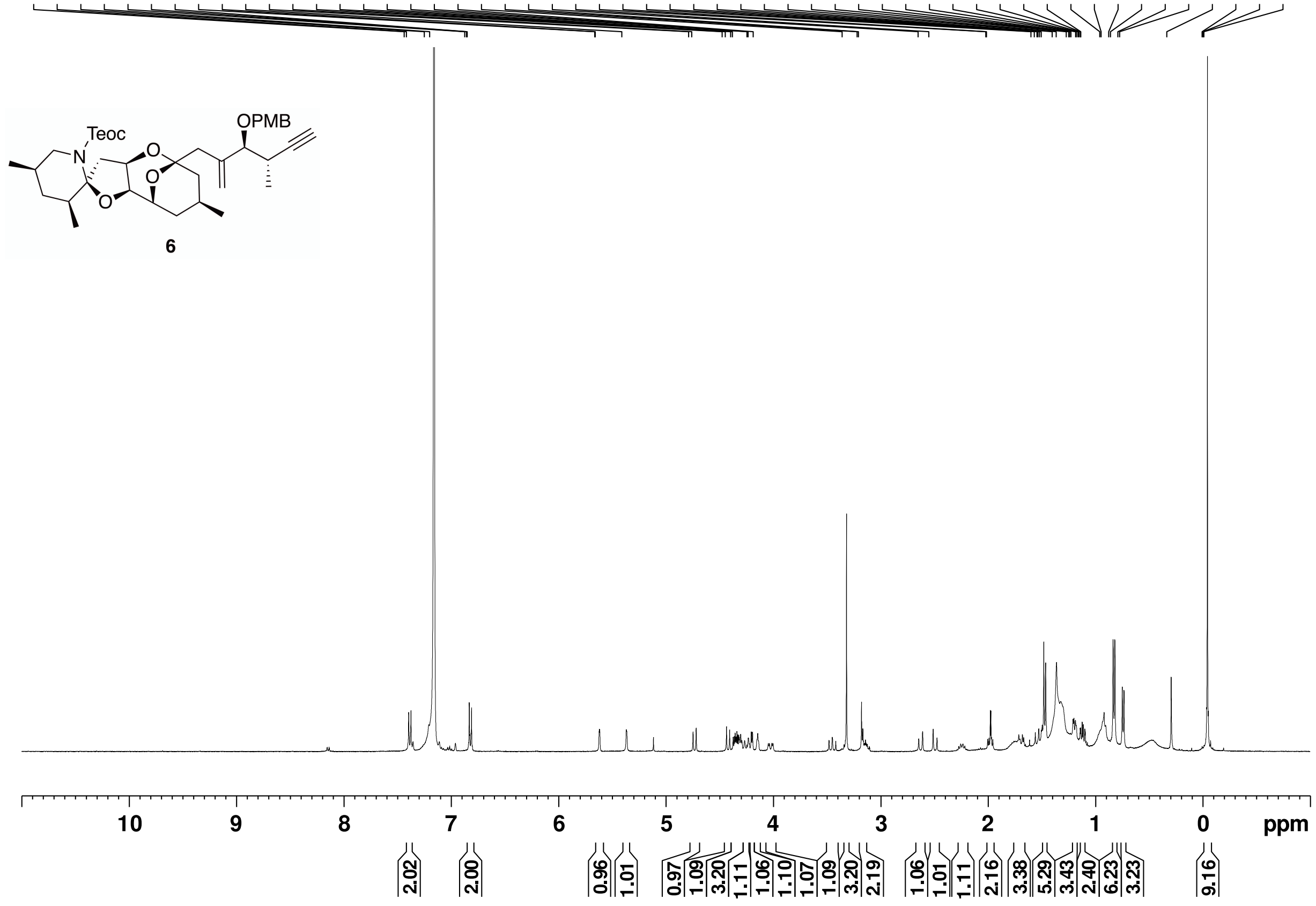